\title{
Soil Mechanics Surface Sampler: Lunar Surface Tests, Results, and Analyses
}

\author{
R. F. SCOTT ${ }^{1}$ ANd F. I. Roberson ${ }^{2}$
}

\begin{abstract}
After the success of Surveyor 1 in meeting the objectives of the engineering flight series, selection from among candidate experiments led to the inclusion of the soil mechanics surface sampler (SMSS) on the Surveyor 3 payload. Although originally planned for later Surveyors, the SMSS was modified to fit the reduced telemetry and commanding capability of Surveyor 3. Specifically, the SMSS was adapted to the mounting location and the electronics interface of the approach television camera. This required a concentrated, short-term effort to modify, build, and test the SMSS to meet the demanding interface requirements. Modifications to the SMSS included removal of the strain-, acceleration-, and position-measuring systems originally planned and incorporation of a means for measuring current drawn by the motors during operation. A description of the modified device, its performance on Surveyor 3, and some conclusions about the lunar surface material are presented in this paper.
\end{abstract}

\section{SUBSYstem Description}

The SMSS subsystem consists of a mechanism, an electronics auxiliary, an installation substructure, and wiring harnesses. The mechanism is an electromechanical device that can pick, dig, scrape, and trench the lunar surface and transport lunar surface material [Scott, 1967]. The electronics auxiliary provides command decoding, data buffering, power management, squib firing, and control of the mechanism, motors, and clutch. The installation substructure supports the mechanism and the auxiliary on the spacecraft. The wiring harnesses provide the electrical interconnections with the spacecraft and between units within the subsystem.

Extension-retraction mechanism. The extension-retraction mechanism is designed to support and position the scoop and to permit operations within the space envelope shown in Figure 1. The mechanism rotates about azimuth and elevation pivot points to provide movement in spherical coordinates.

Drive system. Three electrical motors, operating through appropriate drive trains, furnish mechanical energy to manipulate the SMSS in extension and retraction, azimuth, and elevation. At command from earth, an electrome-

\footnotetext{
${ }^{1}$ California Institute of Technology, Pasadena, California 91109.

${ }^{2}$ Jet Propulsion Laboratory, California Institute of Technology, Pasadena, California 91103.
}

chanical clutch disengages the elevation drive train; the mechanism is impelled downward by a pretensioned elevation torque spring and strikes the lunar surface. A fourth electric motor opens and closes the scoop. The motors and clutch draw electrical power from the spacecraft unregulated bus through the electronics auxiliary, which also provides switch control.

Scoop. The scoop consists of a container, a sharpened blade, and an electrical motor to open and close the container. A small footpad is attached to the scoop door to present a flat surface to the lunar surface. The maximum size of solid lunar material the scoop can hold is approximately $3.2 \mathrm{~cm}$ in diameter; the maximum amount of granular material that can be held is $100 \mathrm{~cm}^{8}$.

Before the Surveyor 3 flight, a test of SMSS motor current versus force calibration was performed on the spacecraft at Cape Kennedy under ambient temperature conditions and at an unregulated voltage of 22 volts. The purpose of this test was to acquire information about mechanical properties of the lunar surface from motor current measurements during SMSS operations on the landed spacecraft.

Motor control. Either a 2 -sec or a $0.1-\mathrm{sec}$ period of operation of any of the motors can be selected by earth command. The angle or distance through which the SMSS moves by these commands depends on the motor involved, its condition, temperature, voltage, and the working load. 


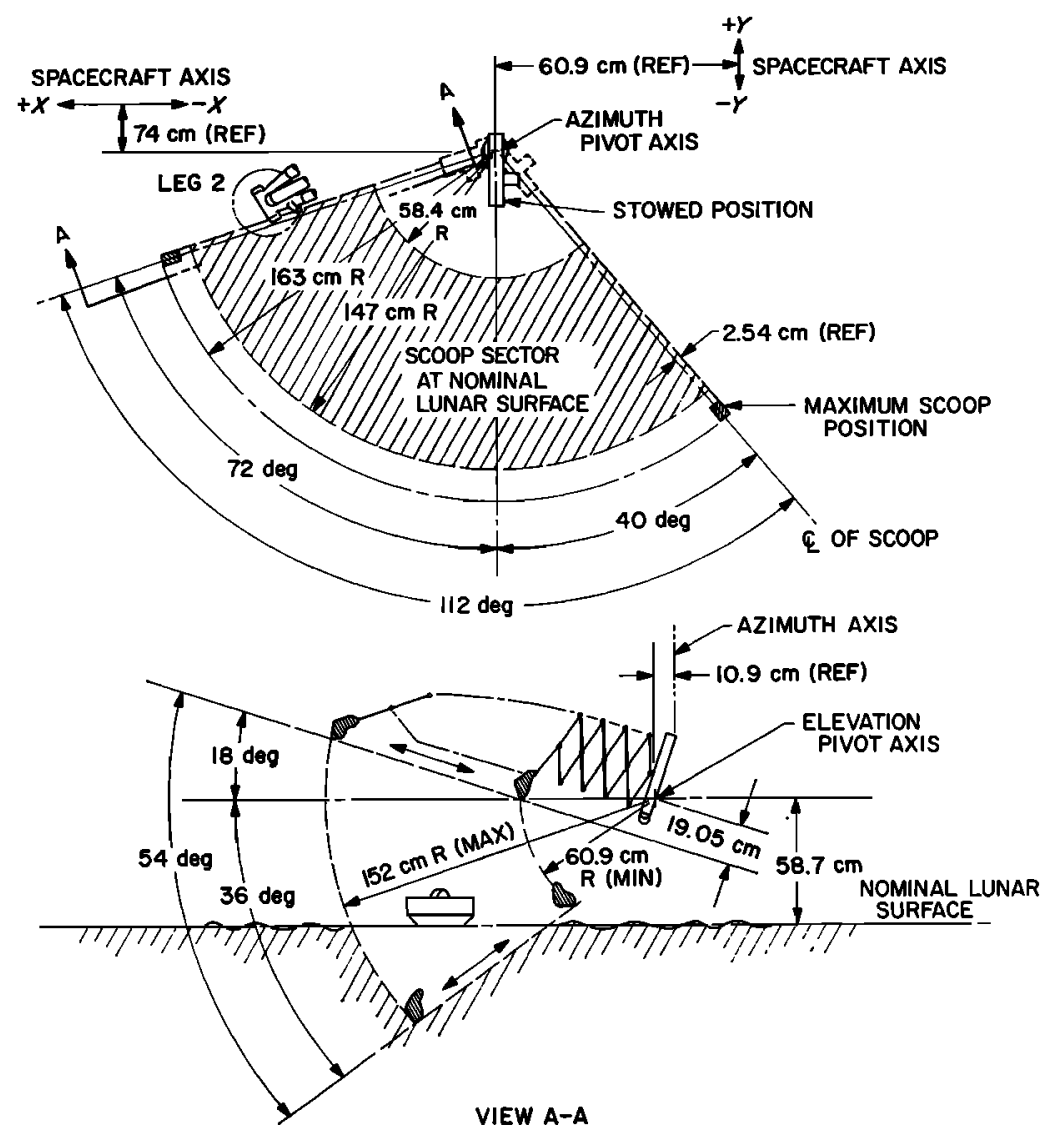

Fig. 1. Space envelope of operation, SMSS mechanism.

\section{Functional and Operational Description}

The SMSS, as modified for Surveyor 3 , was mounted in the location formerly occupied by the approach television camera. This position lies below the survey television camera, between the auxiliary battery and leg 2 , as shown in Figure 2. The area of operation for a nominal surface plane through the three footpads is shown in Figure 1. Because the azimuth axes of the SMSS and the camera are not colinear, the viewing angle of the scoop, through the television system, varies with the scoop's position. When the scoop is positioned near footpad 2, the camera looks directly down the extension arm, which largely obscures the scoop itself. When positioned near the auxiliary battery, a slight side view of the scoop is afforded.

As the SMSS is extended, the angle that the scoop makes with the test surface varies. The extension arm drawing in Figure 1 shows the effect; the photographs of the scoop in contact with the surfaces (Figures $3 a$ and $3 b$ ) show the resulting angle for two extension positions on a nominal, flat surface. The flat surface of the scoop door is normal to the tangential elevation motion at maximum extension.

To make optimum use of operating time during a mission, a standard sequence of testing events has been established. Automatic taped sequences of spacecraft commands have been prepared. They provide the correct motion, based on preflight tests, to accomplish the planned operations. Corrections for variations in motion sizes occurring on the moon are provided by manually commanding the mechanism after a given taped sequence is complete. Table 1 gives the size of each of the motions indicated by preflight calibration. These motion increments occurred at a motor voltage of 22.0 volts and a motor temperature of $70^{\circ} \mathrm{F}$. For com- 


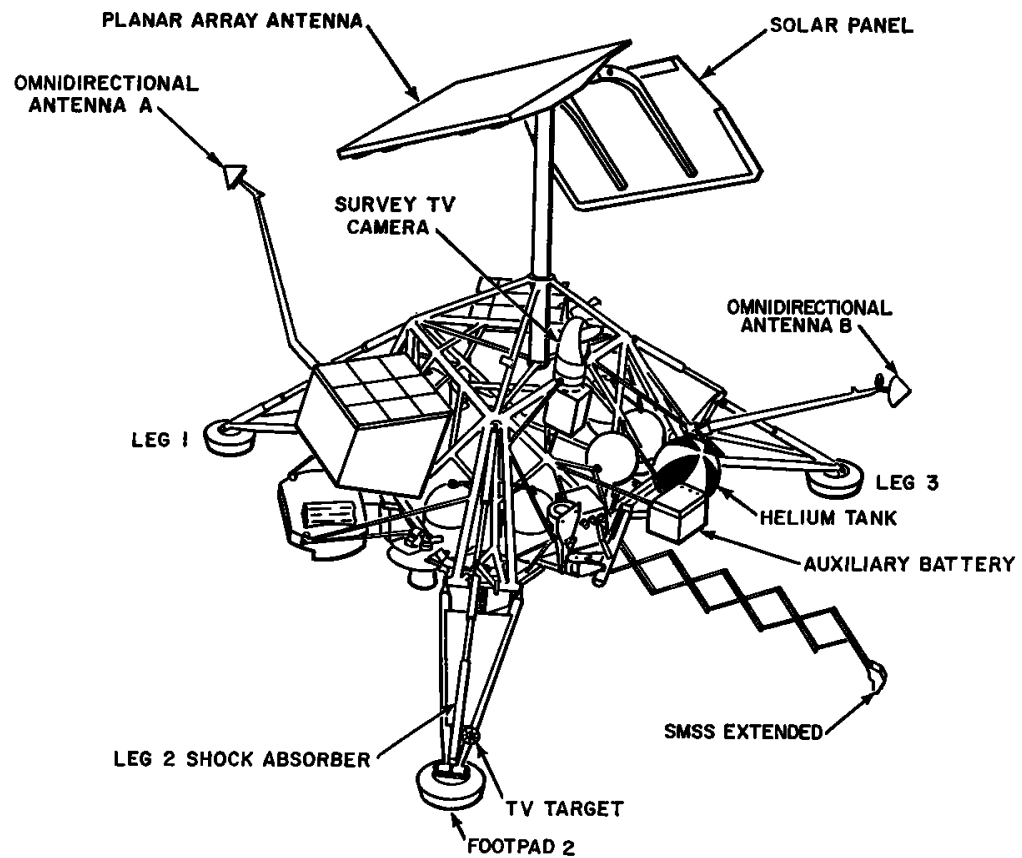

Fig. 2. Surveyor spacecraft, showing SMSS mounted at approach camera location.
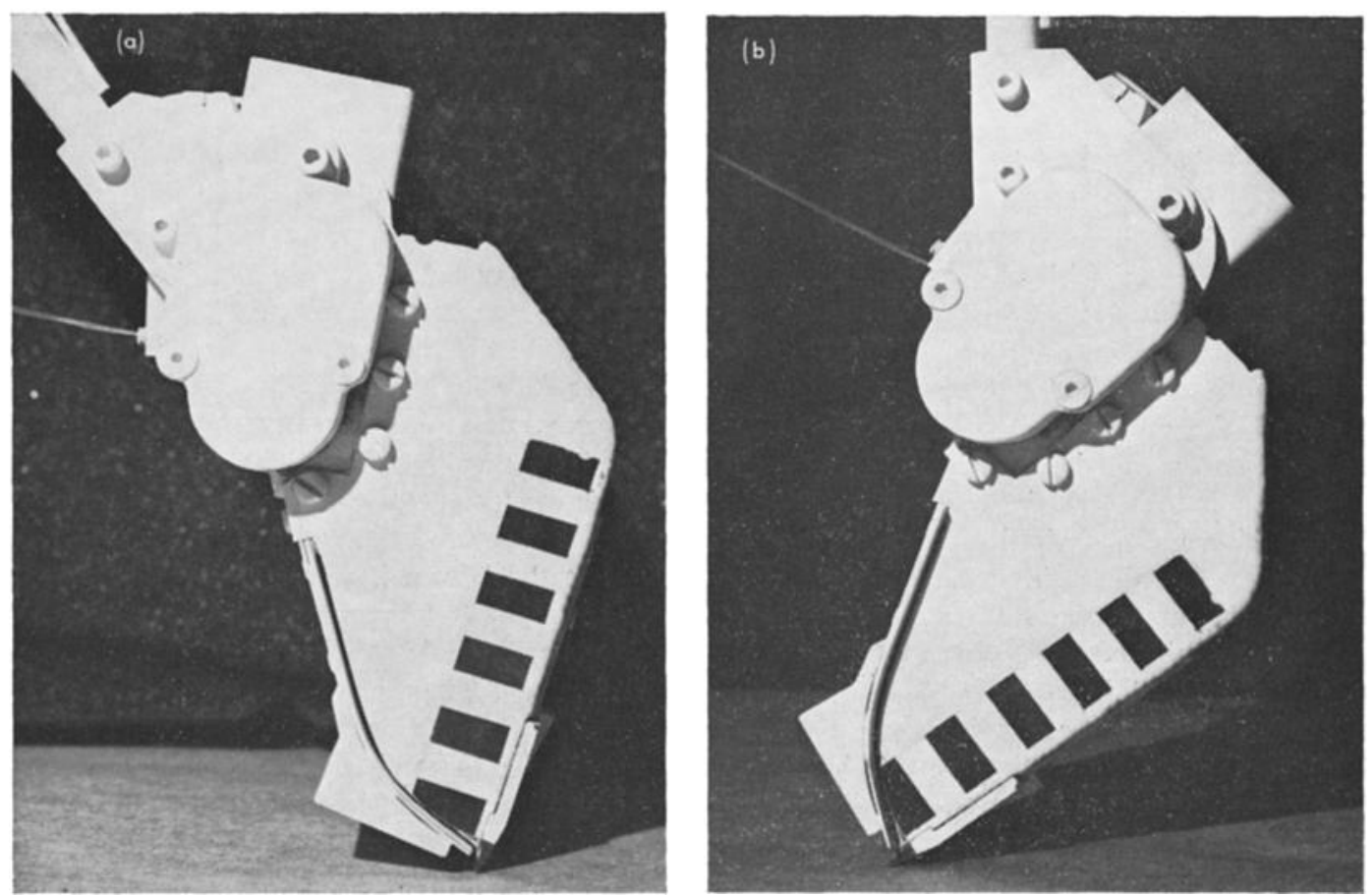

Fig. 3. Photographs showing angle that SMSS scoop door makes with a nominal surface at (a) maximum extension distance and (b) minimum extension distance at which surface can be reached. 
TABLE 1. SMSS Motion Increments (No Load)

\begin{tabular}{lccc}
\hline Motion Time, sec & Nominal Test Value* & $\begin{array}{c}\text { Value on Lunar Surface, } \\
\text { Preliminary Estimate from } \\
\text { TV Observation }\end{array}$ & $\begin{array}{c}\text { Value on Lunar Surface, } \\
\text { from Comparison of } \\
\text { Model and Spacecraft } \\
\text { Functions } \dagger\end{array}$ \\
\hline 2.0 (extend) & $8.6 \mathrm{~cm}$ & $4.4 \mathrm{~cm}$ & $2.5 \mathrm{~cm}$ \\
2.0 (retract) & $8.1 \mathrm{em}$ & $3.8 \mathrm{~cm}$ & $2.2 \mathrm{~cm}$ \\
0.1 (right azimuth) & $1.5^{\circ}$ & $1.5^{\circ}$ & $2.3^{\circ}$ \\
0.1 (left azimuth) & $1.5^{\circ}$ & $\mathbf{1 . 5}^{\circ}$ & $2.5^{\circ}$ \\
2.0 (up) & $6^{\circ}$ & $6^{\circ}$ & $12^{\circ}$ \\
2.0 (down) & $9^{\circ}$ & $9^{\circ}$ & $12^{\circ}$ \\
\hline
\end{tabular}

* Based on unit and system level tests at three extension distances.

$\dagger$ Based on SETL tests using full-scale model spacecraft and television system. Comparison made with day-111 SMSS operations on lunar surface.

parison, the sizes of motion increments estimated during Surveyor 3 lunar operations also are given. More precise calibrations will be made at a later time.

The originally planned initial standard sequence of tests included six static bearing tests and a single trenching operation. Provisions were made for performance of optional tests, based on decisions made during lunar operations. Such optional tests were to include impact tests, picking up rocks, trenching deeper, and bearing tests on subsurface material.

A static bearing test is performed by exercising the extension and azimuth motions until the scoop is positioned above the desired surface point. Then, with the scoop door closed to provide the flat surface for contact, the scoop is driven downward with the elevation motor until the desired penetration is achieved, or until the motor is stalled. An open-scoop static test can also be conducted.

For an impact test the scoop is again positioned above the desired surface point. The elevation drive clutch is actuated, allowing the scoop to drop to the surface, accelerated by gravity and the torque spring attached at the elevation axis. An impact test can be performed with the scoop open or closed.

A trenching operation is performed by driving the scoop down into the surface with the door open, then drawing the scoop toward the spacecraft with the retraction motor. Material can be removed from the trench by retracting the scoop until it is clear of the surface, forming a pile of soil at the foot of the trench, or by closing the scoop and lifting the material out of the trench.

Because position-indicating telemetry is not available, the operations of the SMSS experiment must be monitored closely by the survey television camera. Sequences and priorities for tests, therefore, depend on viewing conditions, spacecraft shadow patterns, and the performance of the television system.

\section{Mission Description}

\section{SMSS Engineering Performance}

The SMSS electronics auxiliary was initially turned on, on day 111; operations were concluded on day 122 .

During the $18 \mathrm{hr}, 22 \mathrm{~min}$ of total on time for the SMSS auxiliary in the first lunar day, 5879 spacecraft commands were transmitted to it. All commands were correctly coded, and 1898 SMSS commands were generated. The SMSS and its electronics auxiliary responded correctly to each command throughout this period.

After touchdown it was found that some of the Surveyor 3 telemetry was not reliable, so that no valid SMSS motor current data could be obtained. The forces applied to the lunar surface by the SMSS had to be estimated from the measured characteristics of the motors when stalled.

\section{Lunar Surface Operations}

Late in Goldstone view period of day 111, it was determined that the temperature of the SMSS electronics auxiliary was high enough 
for operation. The decision to turn on the SMSS power was followed by a short series of tests to assess the condition of the electronics and to attempt a solution of the spacecraft telemetry problems. This section will briefly describe SMSS operations on and after day
111. The locations of all tests are shown in Figure 4.

Day 111. Initial operations began according to the standard sequence and included firing of the pyrotechnic locking device (to release the SMSS from its stored position) and

\begin{tabular}{|c|c|c|c|c|c|c|}
\hline$\nabla$ IMPACT & A & BEARING TEST I & L & BEARING TEST 4 & v & BEARING TEST 7 \\
\hline$\square$ BEARING & B & TRENCH I & M & IMPACT TEST I & $w$ & IMPACT TEST 7 \\
\hline O CONTACT & C & TRENCH 2 & $\mathbf{N}$ & IMPACT TEST 2 & $\mathrm{x}$ & IMPACT TEST $B$ \\
\hline & D & CONTACT I & 0 & IMPACT TEST 3 & $\mathbf{Y}$ & IMPACT TEST 9 \\
\hline & $\begin{array}{l}E \\
F\end{array}$ & BEARING TEST 2 & $\mathbf{P}$ & IMPACT TEST 4 & $\mathbf{Z}$ & IMPACT TEST 10 \\
\hline & $\begin{array}{l}F \\
G\end{array}$ & BEARING TEST 3 & 0 & $\begin{array}{l}\text { IMPACT TEST } 5 \\
\text { MPACT TEST } 6\end{array}$ & $a$ & $\begin{array}{l}\text { CONTACT } 4 \\
\text { IMPACT TEST II }\end{array}$ \\
\hline & H & $\begin{array}{l}\text { TRENCH } 3 \\
\text { CONTACT } 2\end{array}$ & $\begin{array}{l}R \\
S\end{array}$ & $\begin{array}{l}\text { MPPACT TESI } 6 \\
\text { BEARING TEST } 5\end{array}$ & c & IMPACT TEST 12 \\
\hline & I & FOOTPAD CONTACT & $\mathbf{T}$ & CONTACT 3 & d & TRENCH 4 \\
\hline & $\mathrm{J}$ & TRENCH 3 WIDEN & $\mathbf{U}$ & BEARING TEST 6 & e & IMPACT TEST I3 \\
\hline & K & TRENCH 3 WIDEN & & & & \\
\hline
\end{tabular}

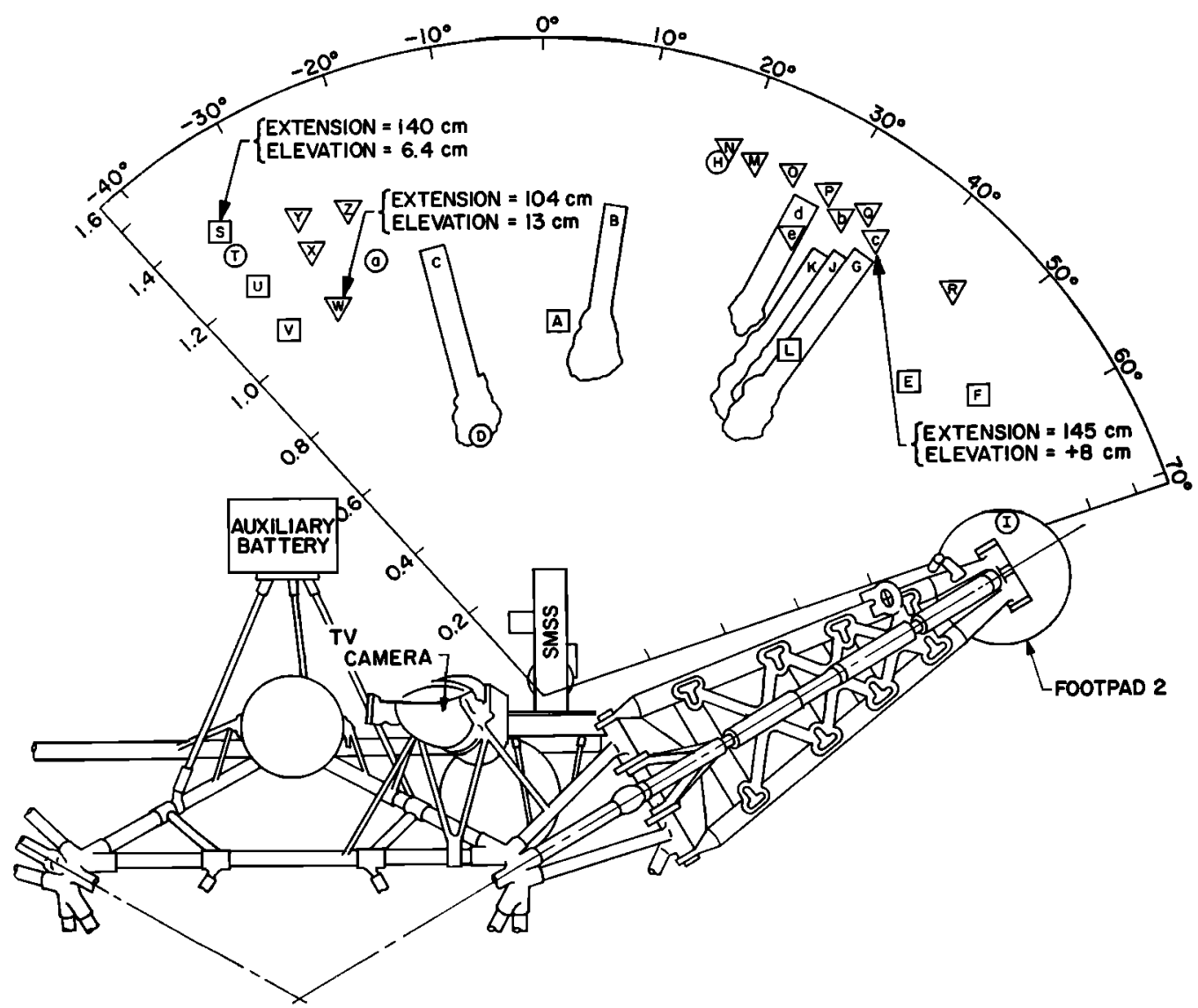

Fig. 4. Plan view of SMSS area of operations, showing location of all surface tests performed during first lunar day of Surveyor 3 mission. Angles are referenced to SMSS axis in stowed position. Extension distance is measured from scoop tip to elevation axis of SMSS; elevation is measured relative to a flat plane through the bottom of the three footpads. 
transmission of four commands to extend the apparatus. A television picture to verify operation of the extension motor showed that extension had occurred but that the extended distance was less than expected.

The sequence of four commands was repeated, and television verified that the SMSS scoop had then reached the originally intended position. A standard sequence that included various commands to extend; to retract; and to move right, left, $u p$, and down was next initiated. Completion of these motions showed that other SMSS motors had operated as specified. The scoop door motor and the clutch actuator were not tested at this time.

Glare in the television optical system, resulting from sun angle, had prevented a complete television survey of the area of SMSS operations. Because narrow-angle coverage was available only for the area near the auxiliary battery, it was decided to depart from the standard sequence. The scoop was extended and positioned above the surface near the auxiliary battery to prepare for the first static bearing test.

The Goldstone view period ended as the bearing test sequence was being initiated; consequently, the SMSS scoop did not contact the surface. The final position of the deployed mechanism on day 111 is shown in Figure 5.

Day 112. It had been intended at the end of day 111 operations to perform the first bearing test on day 112 at the final day 111 position of the SMSS. Before further SMSS operations on day 112 , television surveys were conducted, including a narrow-angle survey of the SMSS operations area. During the television operations, however, problems occurred in azimuth stepping at a time when the camera was stepping clockwise, or to the right azimuth. Accordingly, it was decided to move the SMSS into the field of view of the television camera and to start testing the lunar surface. The surface was located and a command was sent

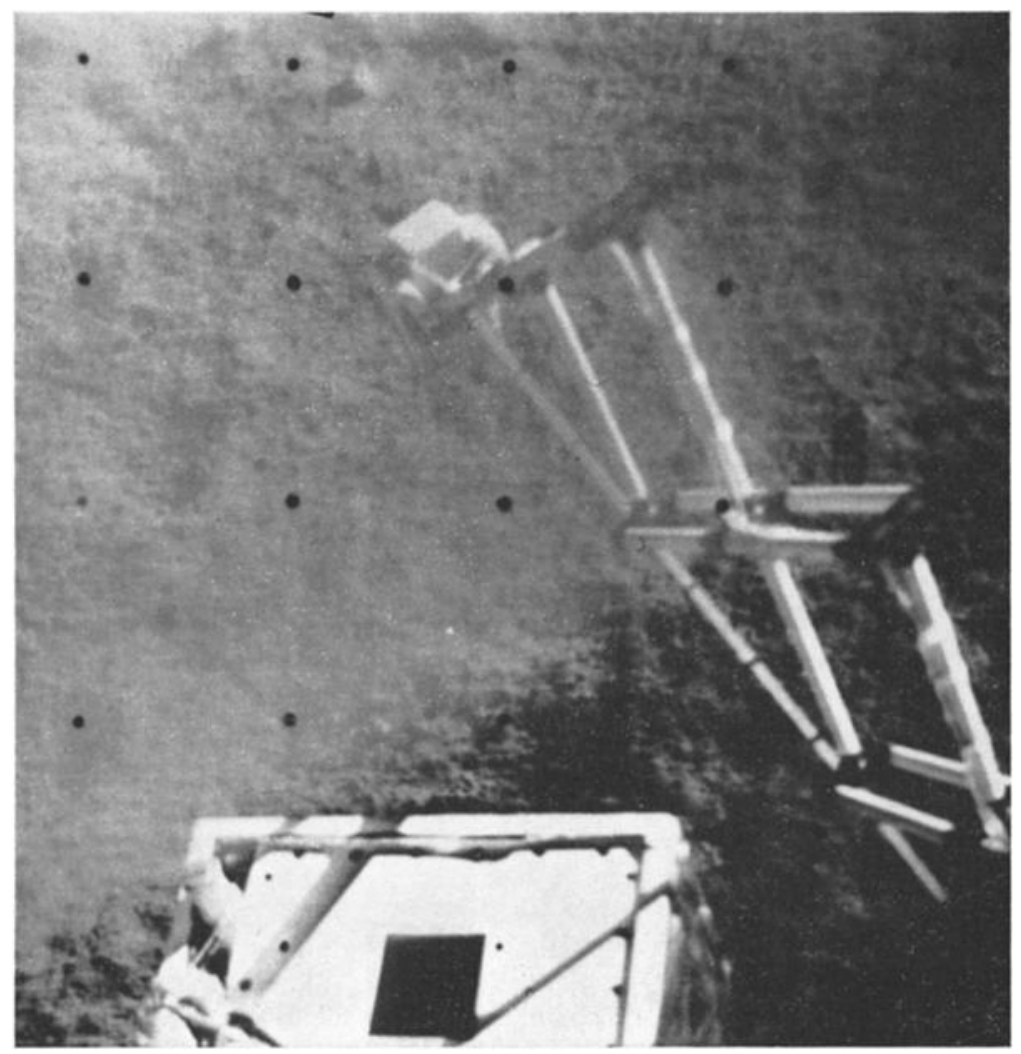

Fig. 5. SMSS deployed and ready for bearing test as Goldstone view ended on April 21, 1967 (day 111, 10h 43m 30s GMT). 


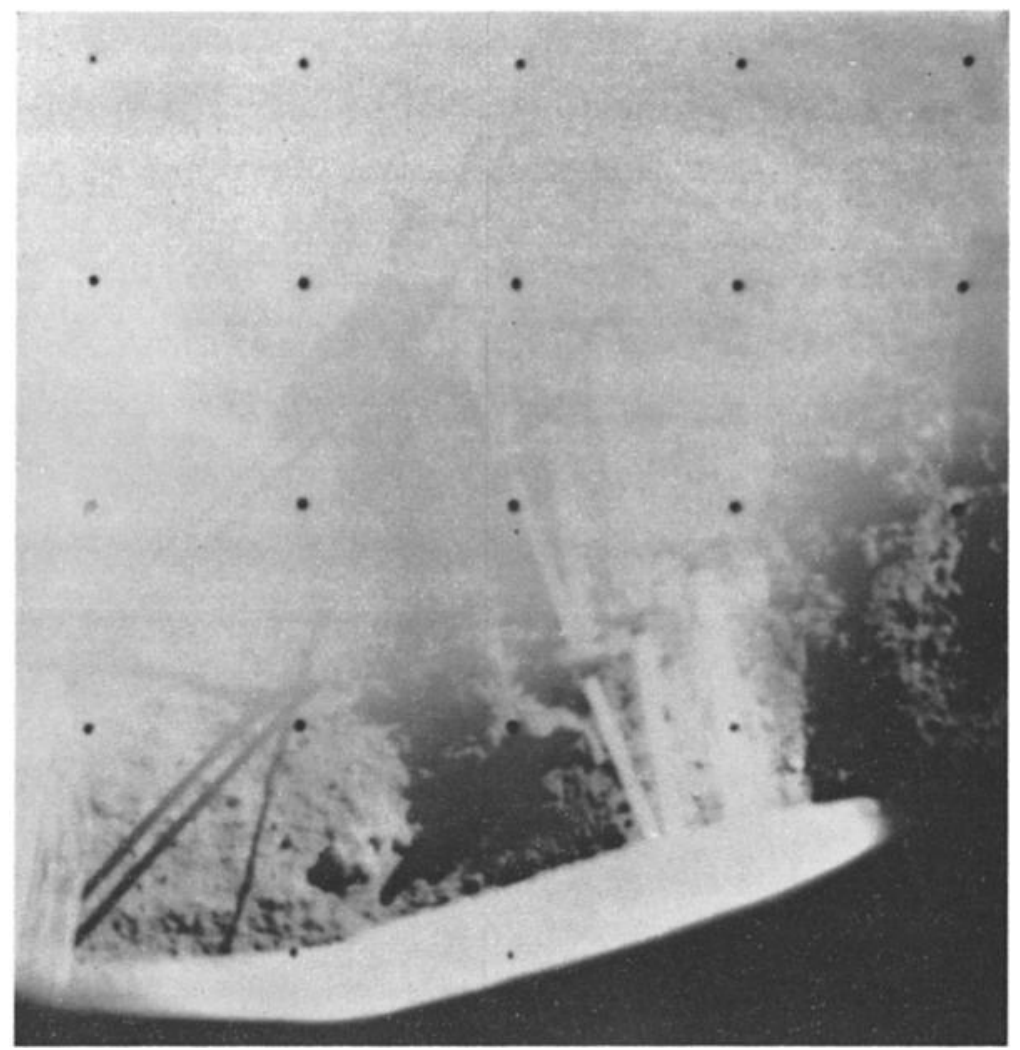

Fig. 6. Final picture of SMSS at completion of operations for April 22, 1967. Trench 1 is visible at right edge of photograph, and trench 2 is directly below SMSS mechanism (day 112 , $11 \mathrm{~h} 34 \mathrm{~m} \mathrm{29s}$ GMT).

to drive the closed scoop into the surface at the site of bearing test 1 , shown as point $A$ in Figure 4. After the scoop was elevated clear of the surface, it was moved right and extended, in preparation for a trenching operation. The scoop was opened for the first time, driven down into the surface, and retracted to form trench 1, located at point $B$ in Figure 4.

Because of the difficulty encountered in the camera stepping, the camera was positioned at $+15^{\circ}$ azimuth, and the SMSS was moved left to this position, near the auxiliary battery. There the camera could follow the retraction motion of the SMSS by stepping its mirror in elevation only. A trench was begun by lowering the scoop (door open) into the surface and retracting it.

At the completion of this trenching operation, which constituted the first pass through trench 2 (shown as point $C$ in Figure 4), the SMSS was elevated, extended to the head of the trench, and driven down into the surface in preparation for the second pass through the trench. After a number of retract commands, television observation revealed that the scoop had traveled only $10 \mathrm{~cm}$, which indicated that it was stalled near the head of the trench.

A narrow-angle survey of trench 2 completed the activities for the day-112 period. Figure 6 shows (in a wide-angle picture) the condition of the operation at the end of the pass; bearing point 1 and trenches 1 and 2 visible.

Day 118. Objectives for this day's operation of the SMSS experiment were to continue in trench 2 to the maximum depth possible.

To clear the scoop of the stalled condition at the head of the trench, it was extended and elevated. Then, retraction and down commands placed the scoop back in the trench, on the spacecraft side of the point of obstruction. Eighteen 2-sec retract commands were 


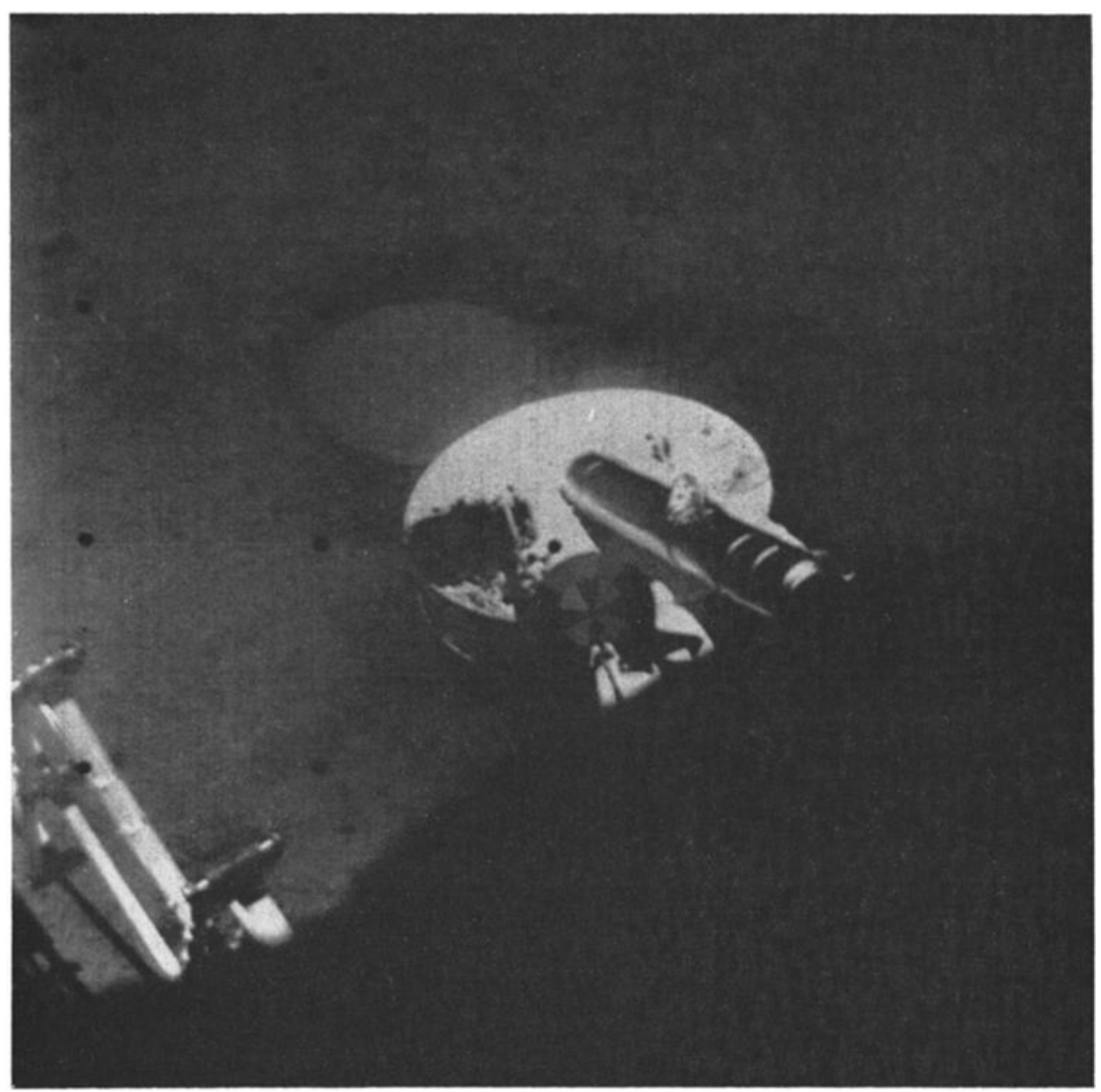

Fig. 7. Wide-angle view of SMSS and footpad 2 (April 26, 1967). Note pile of lunar surface material on top of footpad (day 116, 11h 53m 26s GMT).

transmitted; after a television survey twelve additional transmissions, a sequence of retraction commands, completed the second pass through trench 2.

A television survey of the trench preceded repositioning of the scoop to the head of the trench in preparation for the next drag. The scoop was driven down, again at the head of the trench, and a series of retraction commands was given to complete the third pass through the trench. Television observation showed the scoop traveled less than in the previous trenching pass, indicating loading at the limit of its retraction capacity. The Goldstone view period ended with narrow-angle television surveys of the trench and the SMSS in position at the foot of trench 2.
Day 114. A survey of trench 2 was the only operation performed on day 114 that was related to SMSS. Solar eclipse studies were made.

Day 115. High temperatures precluded SMSS operations during this Goldstone view period.

Day 116. It was decided to restrict SMSS operations to the area near footpad 2 to avoid unnecessary stepping of the television camera mirror.

A study of pictures from the day-113 survey of trench 2 revealed a solid object (contact 1 , point $D$, in Figure 4), possibly a rock, directly beneath the scoop in its last position. Some experiments with a full-scale model spacecraft with an SMSS attached provided a work- 
able sequence of commands to pick up the object without the aid of television, because the camera position precluded narrow-angle viewing of the scoop. The scoop was visible in wide-angle television without violating the stepping constraint. Operations for day 116 began with this sequence, which resulted in closing the scoop door on the object.

Elevation of the scoop revealed that the object had apparently been crushed while being retrieved. It was decided, however, to place the material in the scoop on the surface of footpad 2. The SMSS was extended, rotated right, and viewed through the television system. Because of an uncertainty in the precise extension distance, the scoop was moved left, clear of the footpad, and lowered to the surface, to make a mark indicating its position. After elevating the scoop clear of the surface, study of the mark indicated further extension was required. The extension was performed, and the scoop was moved to make contact with the top of footpad 2. The scoop door was opened; the scoop was elevated and lowered to jar loose the material. The scoop was moved up and to the left to clear the television view of the footpad. The pasition of the SMSS at the end of the operation and the surface material on the footpad are shown in Figures 7 and 8. A narrow-angle color-filter survey of the material was conducted before the end of the Goldstone view.

Day 117. Operations on day 117 consisted of moving left from footpad 2 and extending

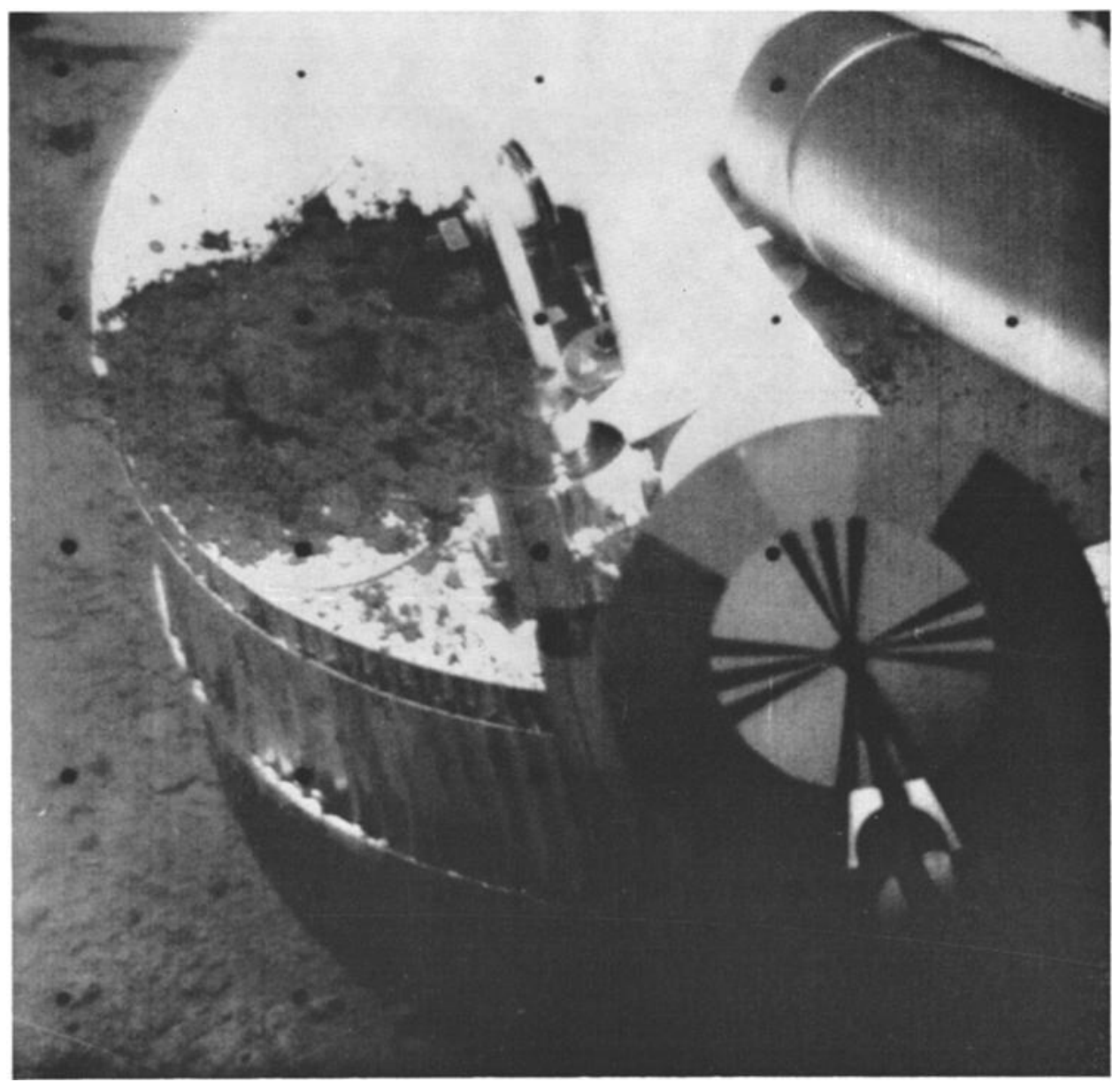

Fig. 8. Material dumped on footpad 2 bv SMSS (April 26, 1967). The color calibration chart is in foreground (day 116, $12 \mathrm{~h} \mathrm{00m} \mathrm{54s} \mathrm{GMT).}$ 


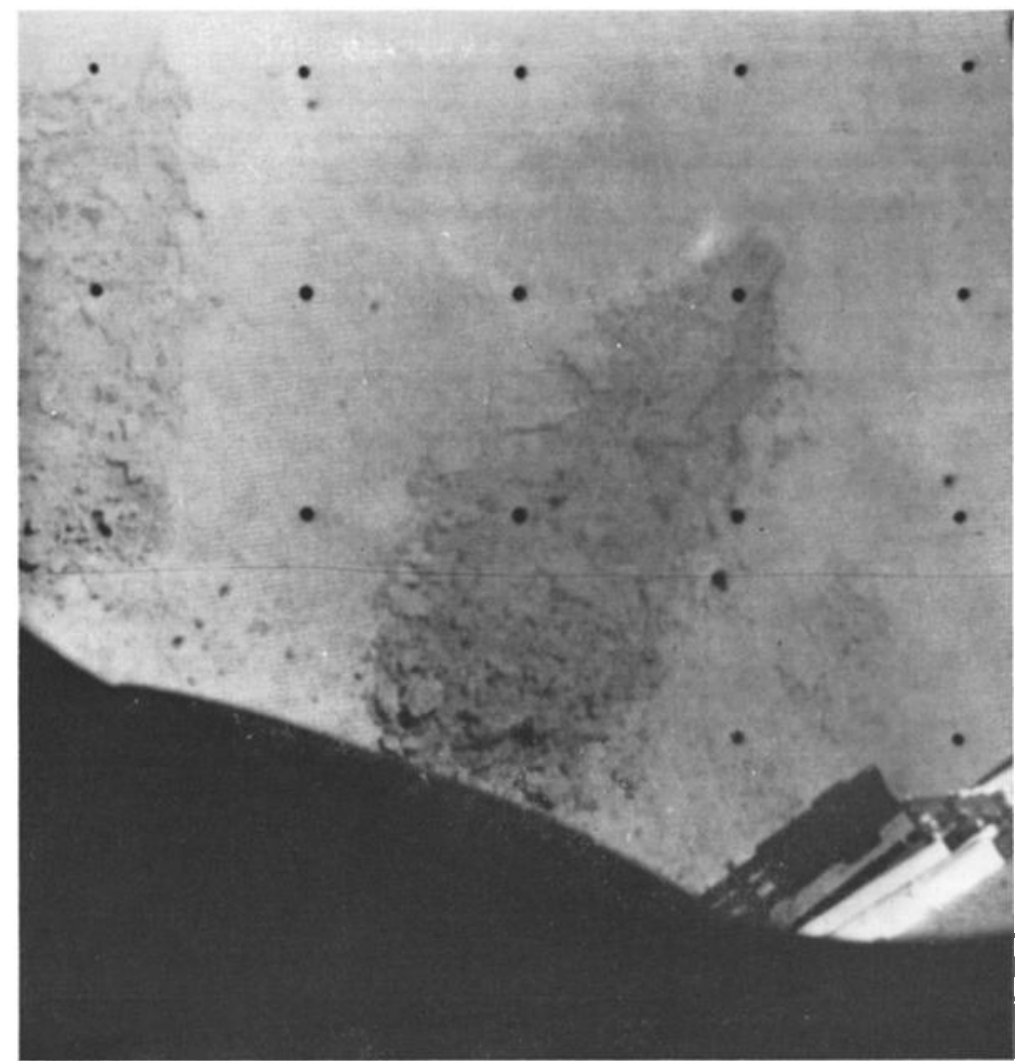

Fig. 9. Wide-angle view of SMSS at end of April 27, 1967, operations. Trench 3 and bearing test 2 are visible on the surface (day $117,10 \mathrm{~h} 34 \mathrm{~m} 53 \mathrm{~s}$ GMT).

the SMSS. Bearing test 2 was then performed. Bearing test 3 was performed next after moving the SMSS farther right with a greater extension. These two bearing tests are located at points $E$ and $F$ in Figure 4.

The SMSS scoop was positioned left and driven into the surface with the scoop open; trench 3 was started. This trench, shown at $G$ in Figure 4, was dug by retracting the SMSS in the 2-sec mode, a total of twenty-six steps. A special series of twenty-six television pictures was taken during this trenching operation, one frame after each retraction step. Figure 9 shows the completed trench 3 and bearing point 2 .

Day 118. At the close of SMSS operations on day 117, an object of higher albedo than the surrounding surface was observed near trench 3, at contact point 2 (item $\mathrm{H}$ in Figure 4). Operations for day 118 began by plac- ing the scoop, with the door open, over the object (Figure 10). With close coordination between narrow-angle television viewing and SMSS commanding, the object was picked up in the scoop.

After positioning the scoop over footpad 2, and opening the scoop door, a short series of 0.1 -sec elevate and lower commands was issued to ensure that the object had been shaken loose from the scoop. This motion freed a portion of soil that had remained in the scoop since the previous trenching operation. Subsequent television observation of the footpad showed the pile of material that had been shaken loose, which apparently had fallen onto and covered the deposited object.

Attempts were made to uncover the object by placing the scoop tip on the footpad and retracting it. This action succeeded in removing some material from the footpad and leav- 
ing an object exposed on the footpad, which was tentatively identified as the one that had been picked up and deposited earlier.

Items $\mathrm{J}$ and $\mathrm{K}$ in Figure 4 represent further trenching operations at trench 3 . The scoop was positioned near the head of the trench to the left and retracted, thus widening the trench to three scoop widths. Figure 11 shows the widened trench, just before bearing test 4 was conducted (item L in Figure 4) in the bottom of the trench.
Day 119. A series of impact tests (shown as items $M$ through $R$ in Figure 4) was performed, starting with a drop from a single 2-sec elevation above the surface at the site of impact test 1. After assessing the impact result, the tests that followed were performed by releasing the scoop from higher positions. Impact tests 2 and 3 were performed by elevating the scoop two 2-sec steps above the surface; impact tests 4,5 , and 6 were acomplished by elevating the scoop four 2-sec steps.

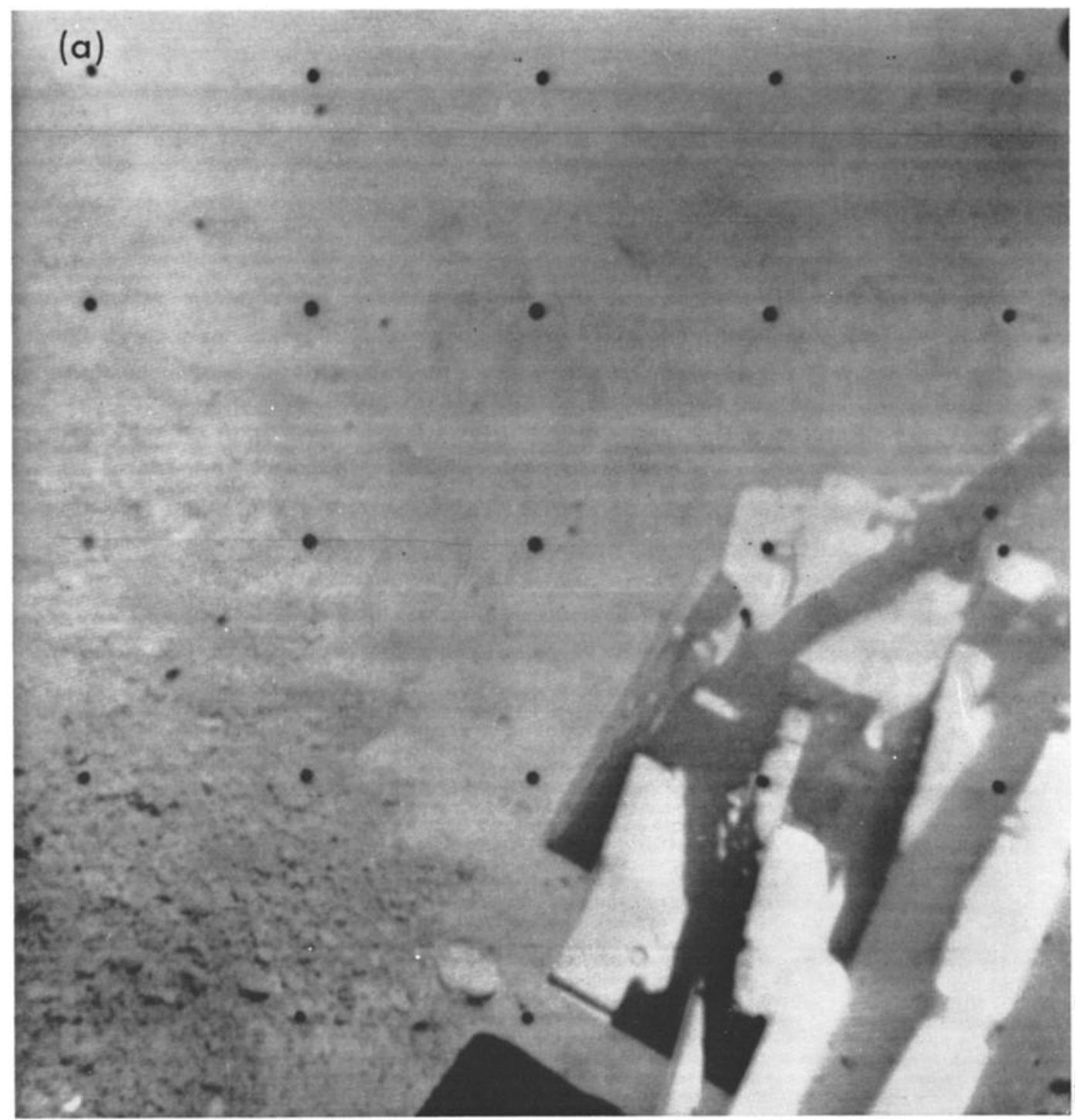

Fig. 10a. SMSS approaching to pick up lighter object (April 28, 1967). Darker material in bottom left corner fell out of scoop in previous movement (day 118, 10h $20 \mathrm{~m} \mathrm{10s} \mathrm{GMT).}$ 


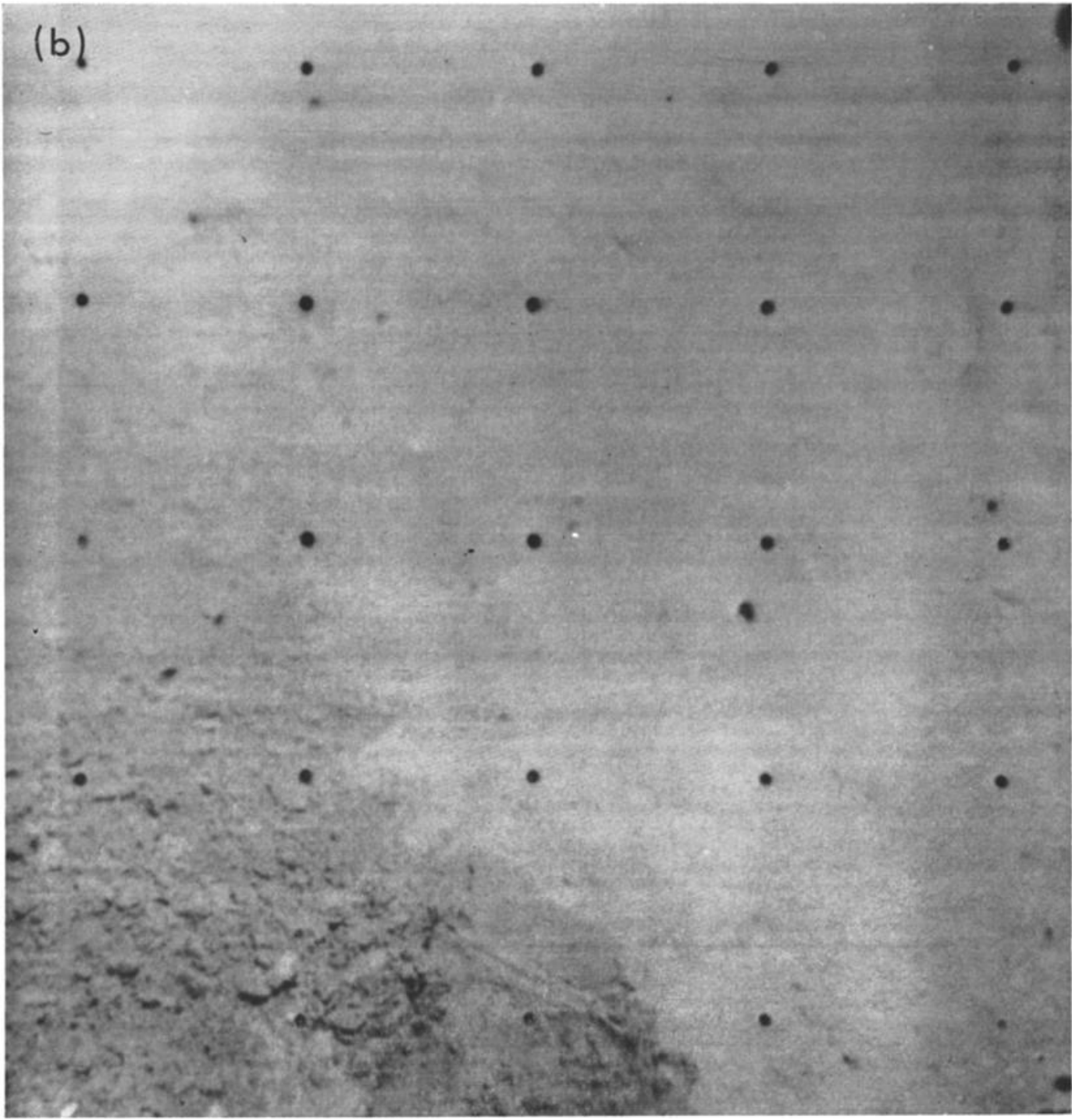

Fig. 10b. Surface after removal of object shown in Figure $10 a$ (day $118,10 \mathrm{~h} 49 \mathrm{~m} 08 \mathrm{~s}$ GMT). The work of the SMSS is clearly seen. Also note that the lighter shade of the surface is lost in the very small disturbance made by the SMSS.

As the conclusion of operations, the SMSS was exercised in several of its operating modes to record the size of motion increments provided by the motors, and to see whether any changes had occurred. There were no changes observed, on the basis of preliminary estimates.

Day 120. SMSS operations were again shifted to the area near the auxiliary battery. The SMSS was extended to near maximum extension, the scoop was closed, and bearing tests 5,6 , and 7 were performed at a single azimuth position. The scoop was retracted between tests. During this bearing test sequence, contact was made with a small surface object (see item $\mathrm{T}$ in Figure 4). The three bearing tests are shown as items $\mathrm{S}, \mathrm{U}$, and $\mathrm{V}$ in Figure 4.

Impact tests 7, 8, and 9 were performed. By stepping the SMSS right and performing extension motions between the test, the three impact points (W, X, and $\mathrm{Y}$ in Figure 4) were placed on a line parallel to the line of the bearing tests. The SMSS was stepped farther right, 
and impact test 10 was performed. Elevations of two 2-sec steps for impact tests 7 and 8 and four 2-sec steps for impact tests 9 and 10 were used.

Day 121. Initial activities involved coordinating the position of the scoop through narrowangle television, and picking up the object (possibly a rock) turned up on the previous day. The object was gripped in the side of the scoop. The scoop was repositioned to afford the best view of the rock (see Figure 12), and a complete color-filter survey was made. While positioning the scoop to place the object on the surface nearby (because the camera could not at this time be moved to view footpad 2), the object slipped out and was not seen again.

Three new trenching passes were made through trench 2. Before the last pass, four impacts with the scoop open were made in the trench bottom to loosen the material, since an increas- ing number of commands had been required for each successive pass. Figure 13 shows the SMSS scoop with the rock in the door; bearing tests 5,6 , and 7 from previous operations are also visible.

Sun angles for day 122 dictated the moving of SMSS operations to the right, where available light permitted tests and where minimum camera stepping would be required to follow sunset shadows. The television camera was moved successfully.

Impact test 11, at position b in Figure 4, was performed on the undisturbed surface with the scoop open, following a 2-sec elevation movement. Another test from the same height, impact test 12, was repeated at position c because material deposited from the scoop on the surface in impact test 11 obscured the surface at point b. A short trench was dug at point d, followed by impact test 13 at location $e$ in the

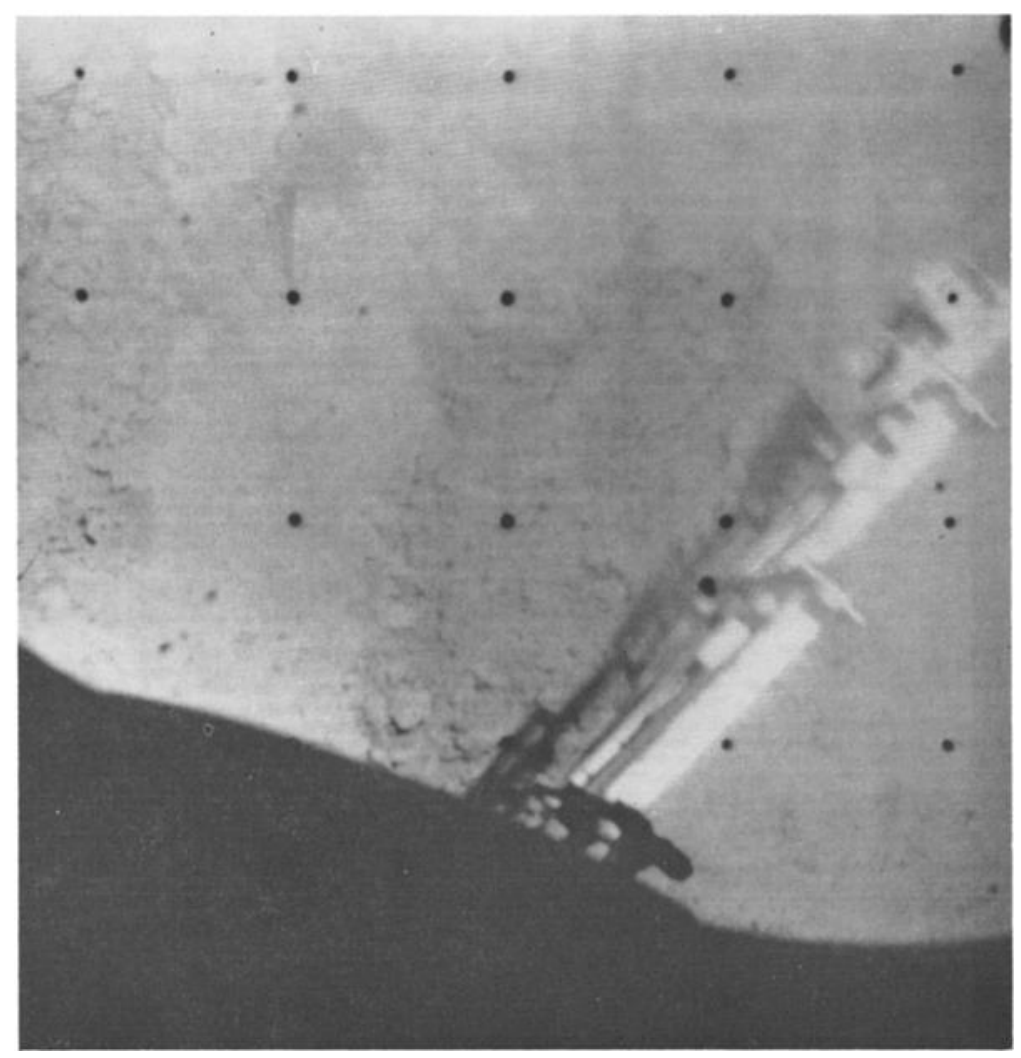

Fig. 11. Trench 3, widened, with SMSS scoop poised and ready for bearing test 4 in trench bottom (April 28, 1967). SMSS appears blurred because of motion when picture was taken (day 118, 13h 21m 33s GMT). 


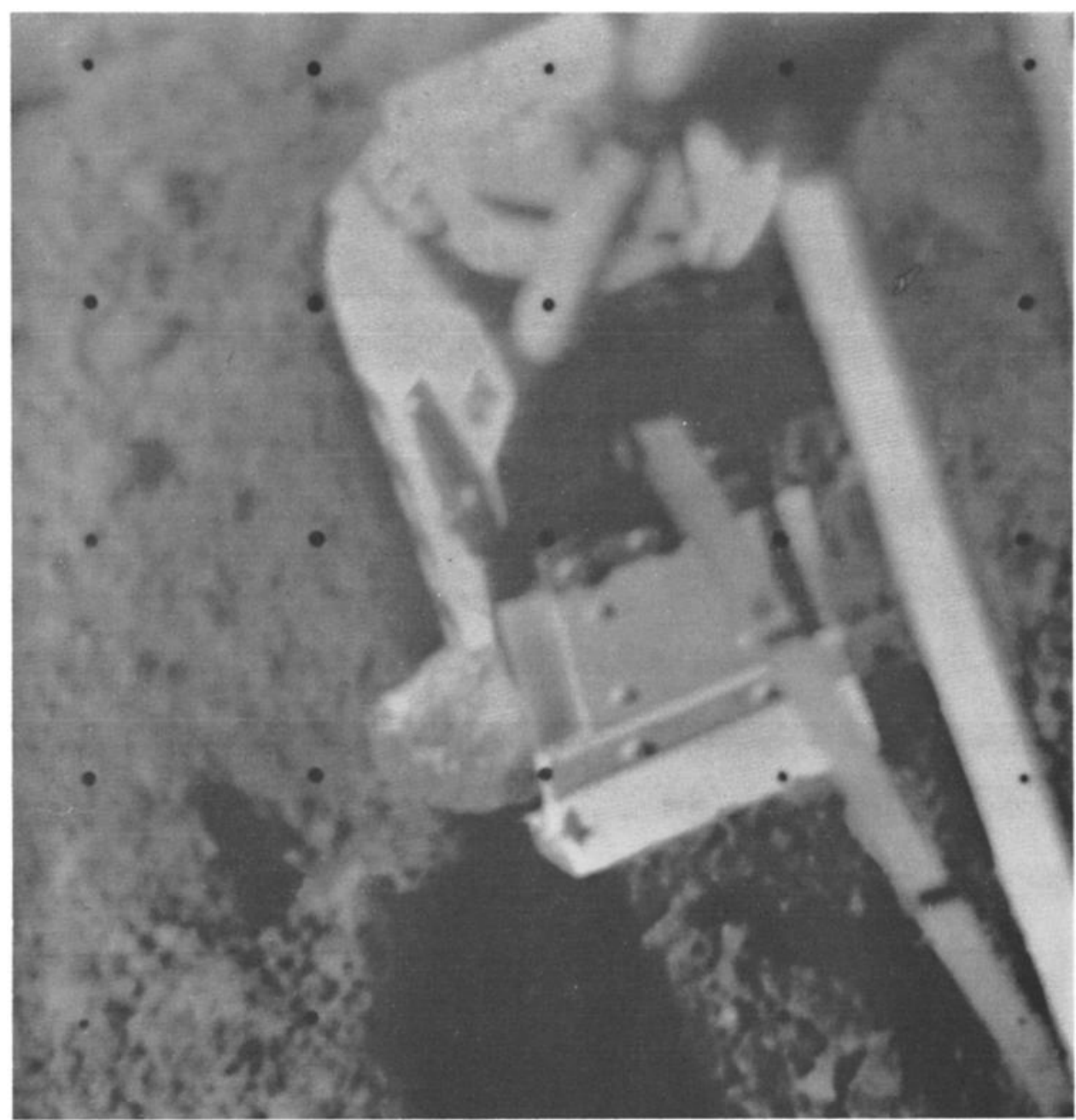

Fig. 12. Close-up picture of 'rock' extracted from lunar surface and being held by SMSS on May 1, 1967 (day 121, 15h 18m 39s GMT).

trench bottom on subsurface lunar material. The final position of the SMSS, with trench 4 and several impact points visible on the surface below, is shown in Figure 14.

Operations are summarized in Table 2. A television picture mosaic (Figure 15) shows the area and results of operations in trench 1 (Figure 4, item B).

In summary, the second trench, which was along an azimuth line that facilitated camera coverage, was worked on three separate Goldstone view periods (Table 2). The progress of trench formation is shown in television picture mosaics. Figure 16 shows the area before trenching operations began. The initial pass ended in the condition shown in Figure 17. On the second pass, the SMSS scoop was extended slightly beyond the end of the first trench (Figure 18), and the subsequent series of retract commands resulted in a short travel (Figure 19). During day 113 , the SMSS was removed from its position in the second trench (Figure 4, item C) and a trench survey was performed (Figure 20). Two additional trench attempts resulted in the formation of the trench to the condition shown in Figure 21, a survey performed during day 114. Figure 22 is a general area survey showing trench 2 under lighting conditions of day 120 . It should be noted that additional work was done in trench 2 on day 121. 


\section{Performance}

Reconstruction of the experiment sequences performed on the moon has begun on a fullscale model of Surveyor 3 in the Surveyor Experiment Test Laboratory (SETL).

Through the use of a Surveyor television system on the model spacecraft, a picture of the SMSS from Surveyor 3 can be duplicated by manipulating the SMSS model until the picture matches. An examp'e of this technique is shown in Figure 23. Once the SMSS is aligned to match the lunar pictures, measurement of the extension, azimuth, and elevation can be made directly.

Motion increments of the SMSS on Survevor 3 have been determined in this way for the initial checkout sequence. Results are compared with preliminary estimates in Table 1. Similarly, the position of surface points can be determined, and positions of three points are noted in Figure 4. As additional points are measured, allowing cross checks, these positions will be refined.

\section{Tests on Lunar Surface Material}

Results of tests performed on the lunar surface by the SMSS and conclusions on the mechanical properties of the surface material, as deduced from the test results, are presented here.

Tests performed. Many mechanical tests

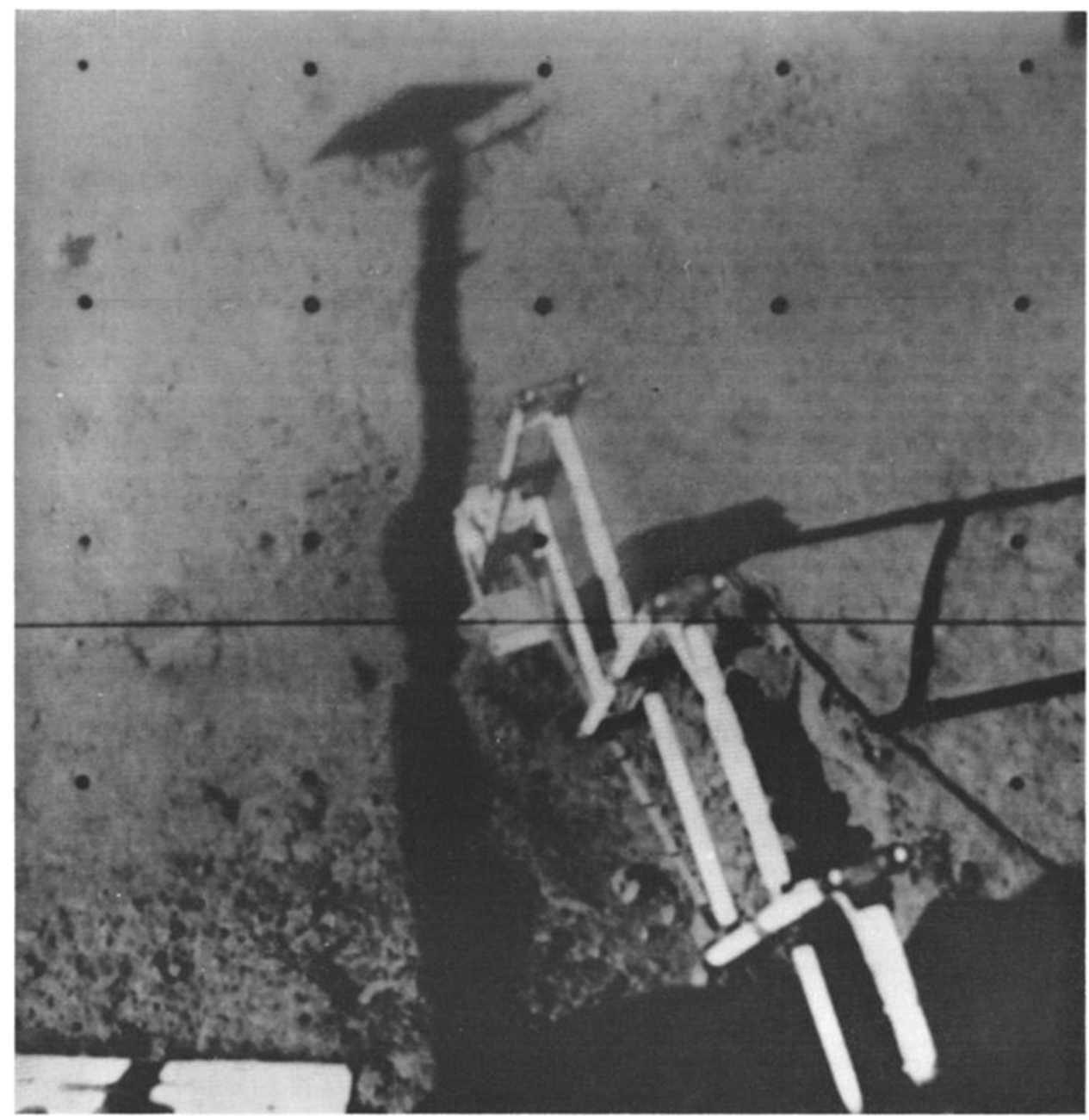

Fig. 13. SMSS with small 'rock' in scoop. Rock was picked up on May 1, 1967. On the surface below, several bearing test points are visible (day 121, 14h 56m 38s GMT). 


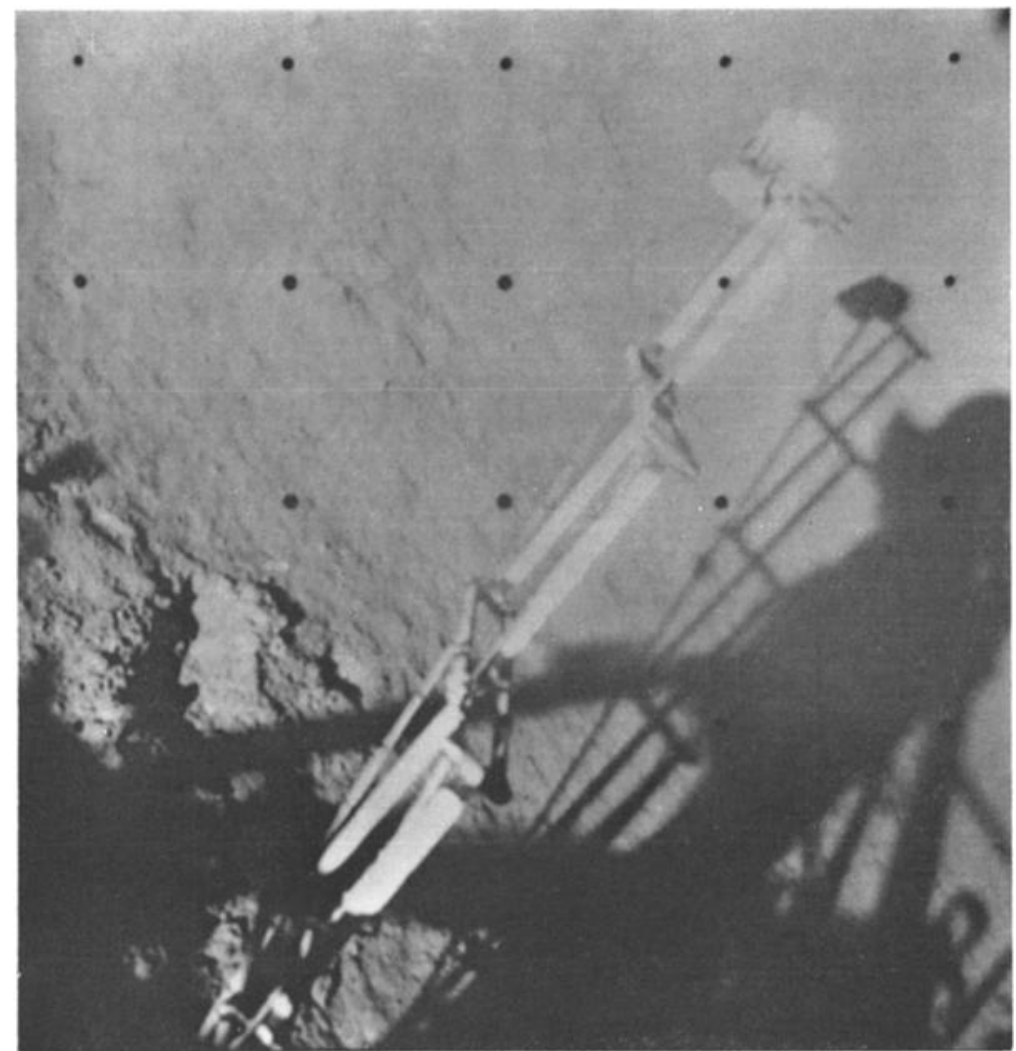

Fig. 14. Final position of SMSS at conclusion of lunar operations on May 2, 1967. Trench 4 and several impact points are visible on the lunar surface (day 122, 14h 20m 11s GMT).

TABLE 2. Summary of Operations

\begin{tabular}{|c|c|c|}
\hline Day & Operation Performed & $\begin{array}{l}\text { Item in } \\
\text { Figure } 4\end{array}$ \\
\hline 111 & Deploy and check motors & \\
\hline 112 & Bearing test, two trenches & A, B, C \\
\hline 113 & Continue second trench & \\
\hline 116 & Place material on footpad 2 & D \\
\hline 117 & $\begin{array}{l}\text { Two bearing tests, third } \\
\text { trench }\end{array}$ & $\mathrm{E}, \mathbf{F}, \mathbf{G}$ \\
\hline 118 & $\begin{array}{l}\text { Pick up object, place on } \\
\text { footpad, widen third } \\
\text { trench, bearing test } \\
\text { in trench }\end{array}$ & $\mathbf{H}, \mathbf{J}, \mathbf{K}, \mathbf{L}$ \\
\hline 119 & $\begin{array}{l}\text { Six impact tests, calibrate } \\
\text { motions }\end{array}$ & $\begin{array}{l}\mathrm{M}, \mathrm{N}, \mathrm{O}, \mathrm{P}, \\
\mathrm{Q}, \mathrm{R}\end{array}$ \\
\hline 120 & $\begin{array}{l}\text { Three bearing tests, four } \\
\text { impact tests, move } \\
\text { small rock }\end{array}$ & $\begin{array}{l}\text { S, T, U, V, } \\
\text { W, X, Y, } \\
\text { Z, a }\end{array}$ \\
\hline 121 & $\begin{array}{l}\text { Pick up rock, continue } \\
\text { second trench }\end{array}$ & $\mathrm{a}, \mathrm{C}$ \\
\hline 122 & $\begin{array}{l}\text { Two impact tests, fourth } \\
\text { trench, impact in trench }\end{array}$ & $\mathbf{b}, \mathbf{c}, \mathrm{d}, \mathbf{e}$ \\
\hline
\end{tabular}

were performed with the SMSS from which calculations of varying degrees of refinement can be made. In this paper, only preliminary estimates of material properties are given, based on a brief evaluation of the SMSS behavior and the photographic results. A summary of the tests from which mechanical properties can be derived is given in Table 3.

Bearing. Eight bearing tests were made with the SMSS door in the closed position so that an area $5 \times 2.5 \mathrm{~cm}$ was presented to the lunar surface. As seen in Figures $3 a$ and $3 b$, the angle that the flat base of the scoop makes with the lunar surface varies with the extension distance of the SMSS. Only in the extreme extension position is the flat base aligned approximately parallel to the surface. Consequently, as the scoop is pushed into the surface in the bearing tests, the material under the scoop is forced down and the surface toward the spacecraft is observed to rise as the soil is displaced as shown in Figure 24. 
When each trench was begun, the scoop was pushed into the lunar surface with the door open wide to enable a much smaller area to be presented to the surface. These tests have not been analyzed, and no results from them are shown in Table 3, although penetrations of 3.8 to $5 \mathrm{~cm}$ were obtained.

As a result of the varying temperatures dur- ing the lunar day and the different distances of extension of the SMSS, a range of forces can be applied to the lunar surface by the tip of the scoop. It was originally intended that these forces be obtained directly by measuring the motor currents and using the preflight calıbration data. The absence of usable telemetered information on spacecraft motor currents pre-

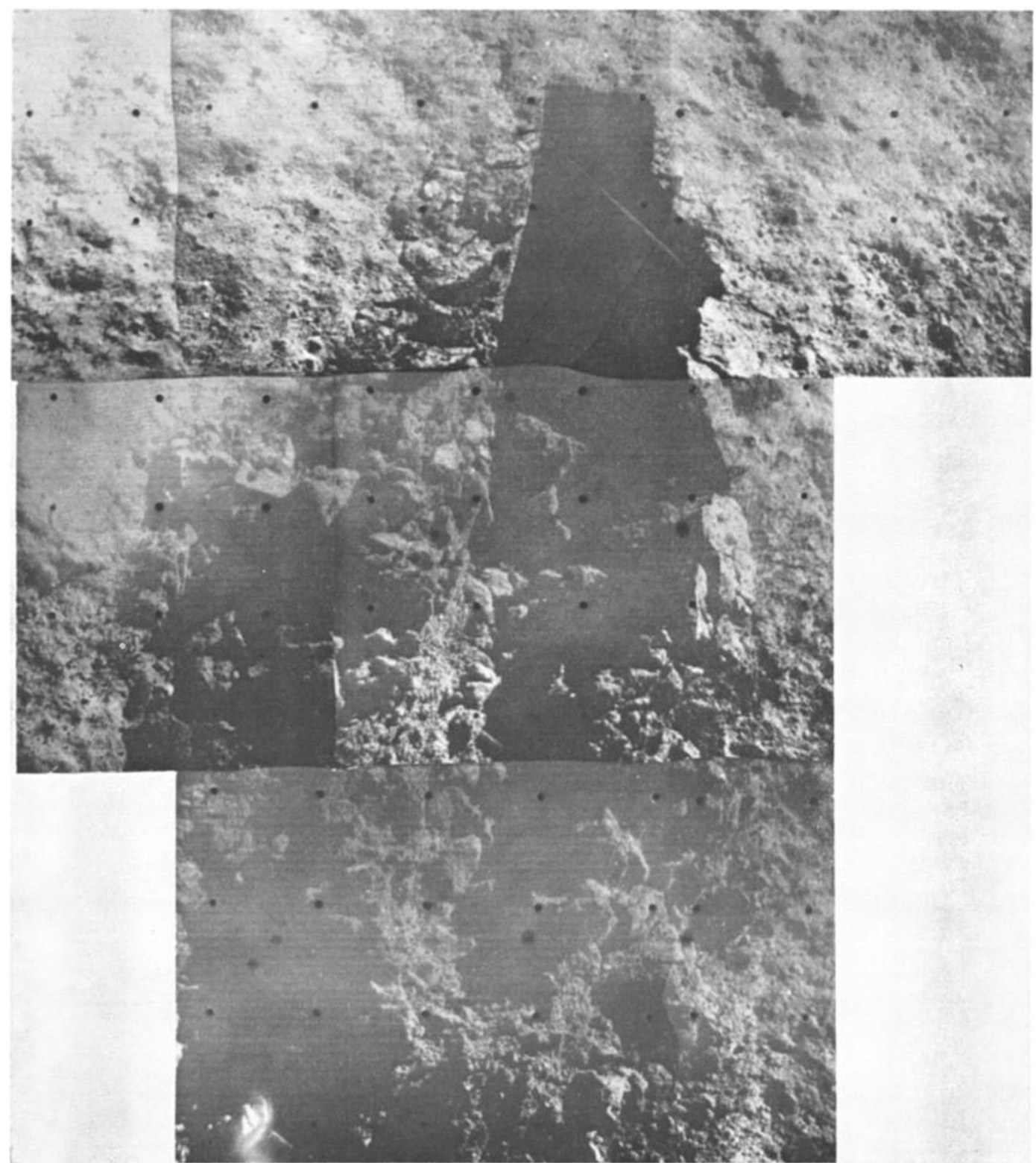

Fig. 15. Mosaic of first trench dug by SMSS on April 22, 1967 (day 112, 07h 22m 49s to 08h 33m 28s GMT). 


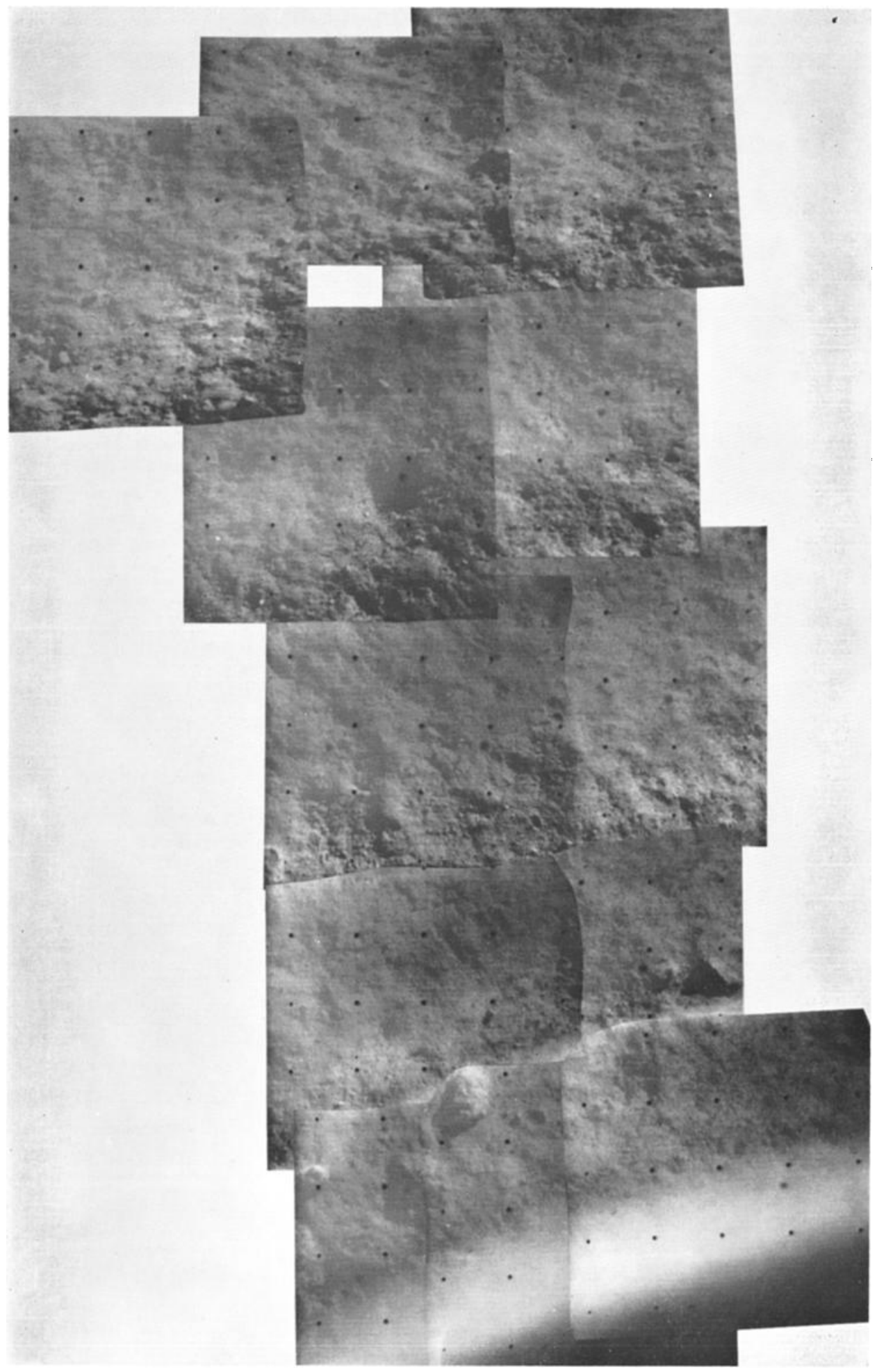

Fig. 16. Area where second trench was dug by SMSS on April 21, 1967, before disturbance (day $111,09 \mathrm{~h} 23 \mathrm{~m} 55 \mathrm{~s}$ to $09 \mathrm{~h} 28 \mathrm{~m} 24 \mathrm{~s}$ GMT). 


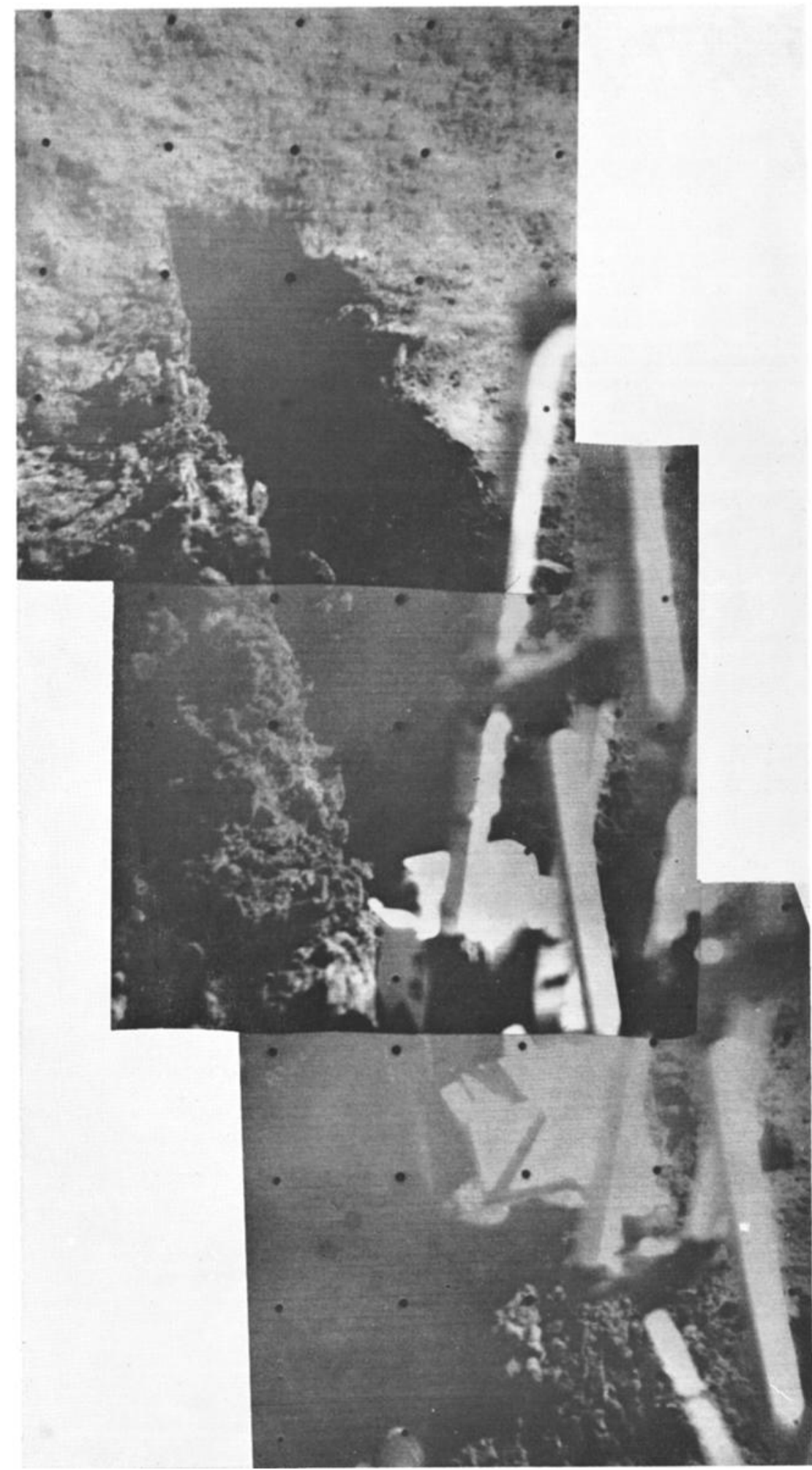

Fig. 17. Second SMSS trench mosaic with SMSS in position after first pass through trench on April 22, 1967 (day 112, 11h 18m 00s to $11 \mathrm{~h} 19 \mathrm{~m} 33 \mathrm{~s}$ GMT). 


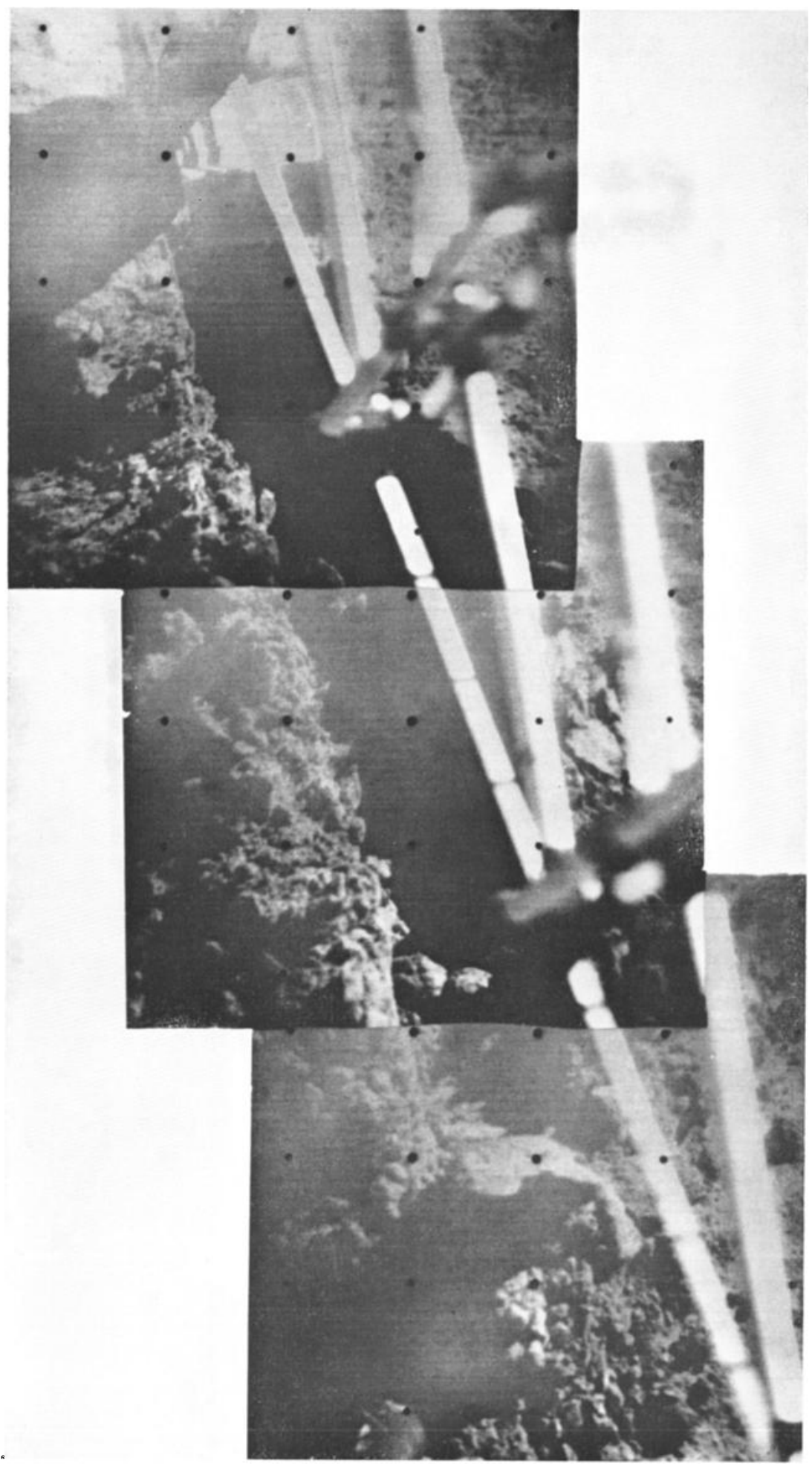

Fig. 18. SMSS positioned ready for second pass in trench 2 (day $112,11 \mathrm{~h} 24 \mathrm{~m} 42 \mathrm{~s}$ to $11 \mathrm{~h}$ $25 \mathrm{~m}$ 59s GMT). 


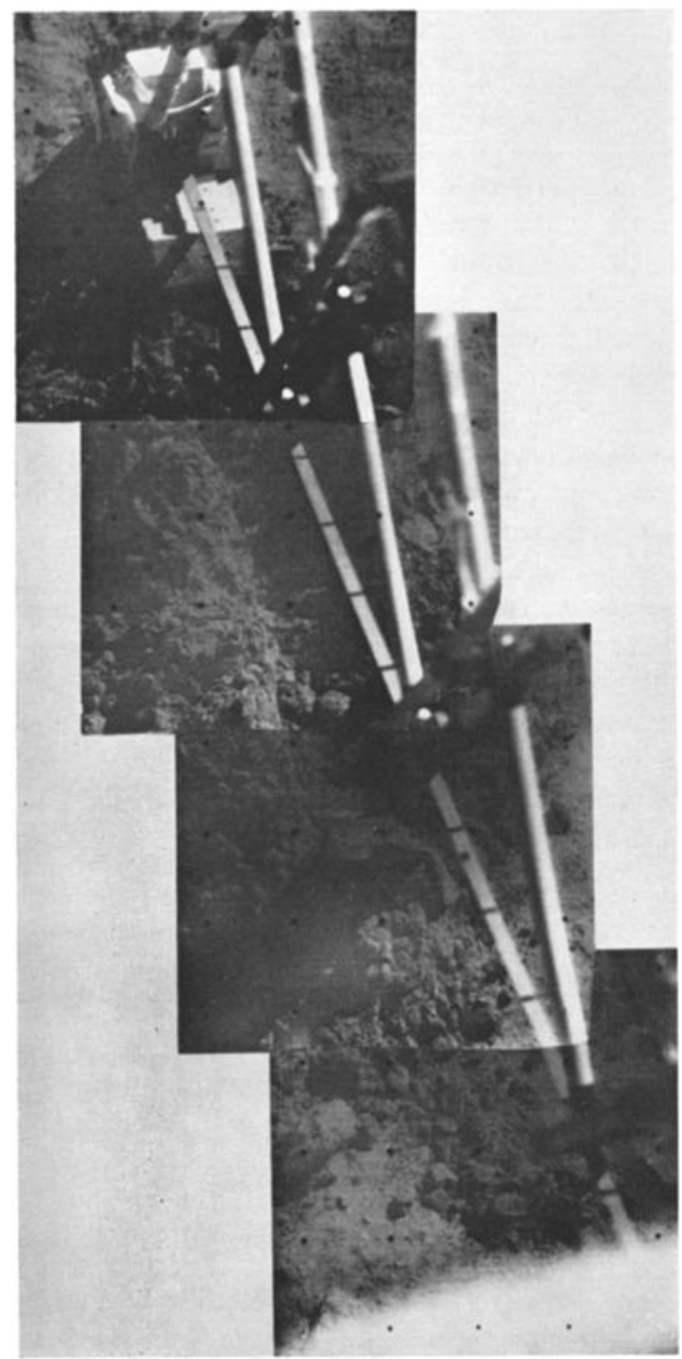

Fig. 19. Stalled position of SMSS in second trench after second attempt to trench on April 23, 1967 (day 113, 11h 24m 42s to $11 \mathrm{~h} 25 \mathrm{~m}$ 59s GMT).

cluded this intention, however. The motors did not have temperature sensors; therefore, it was necessary to estimate motor temperatures from the temperatures measured on the spacecraft and from temperature differences assumed from preflight tests. The information on forces in the bearing tests shown in Table 3 was obtained from such estimates of motor temperatures and from the known extension distances of the SMSS.

After each test television pictures were taken of the SMSS scoop in the lunar surface and of the disturbed surface after removal of the scoop. Other pictures were obtained of each surface disturbance at various sun angles on succeeding days. These pictures have been used to obtain the penetration distances given in Table 4 for bearing and impact tests.

Before some bearing and impact tests, the SMSS was lowered to the lunar surface by 0.1 -sec down commands to determine the surface location at the point. The commands were

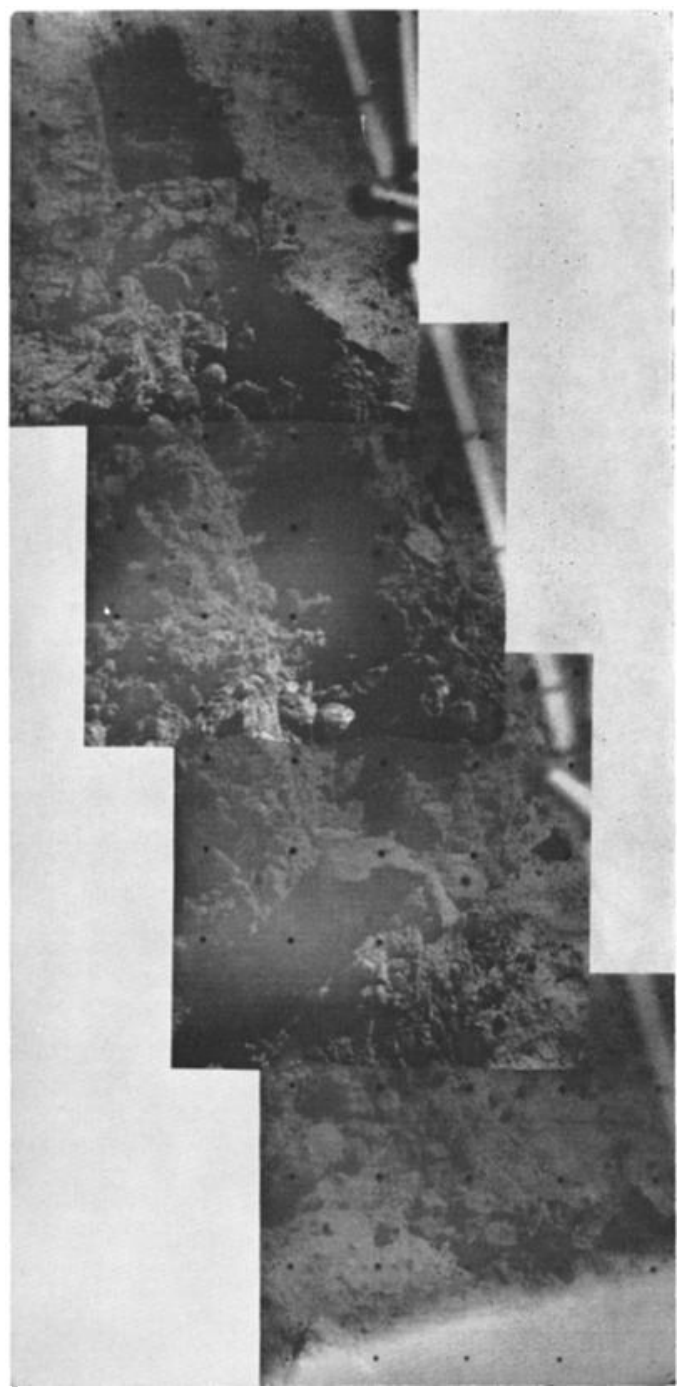

Fig. 20. Mosaic of trench 2 after SMSS has been removed following stalling at far end (April 23, 1967), where material from scoop has been dumped (day 113, 06h 39m 01s, 06h $40 \mathrm{~m} \mathrm{05s,06h}$ 40m 38s, and 06h 41m 08s GMT). 


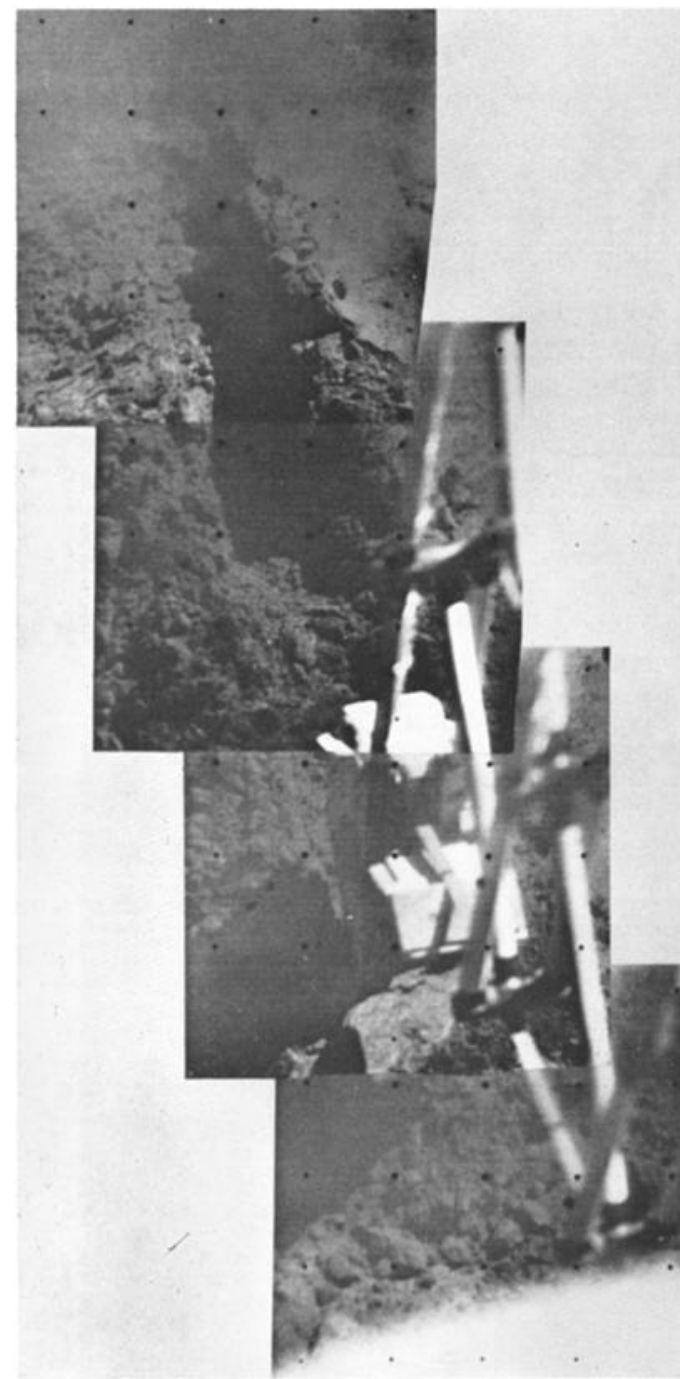

Fig. 21. Second trench after two additional drags through it on April 24, 1967 (day 114, 05h $10 \mathrm{~m} 33 \mathrm{~s}$ to $06 \mathrm{~h} 18 \mathrm{~m}$ 51s GMT).

repeated until no further downward motion was detected. Although these operations imposed loads of $10^{5}$ dynes on the surface, only a small amount of disturbance caused by the blade tip was observed.

Trenching. Three trenches were dug in the lunar surface with the SMSS. The first trench was excavated with only a single pass of the SMSS, whereas trenches 2 and 3 were subjected to repeated passes. A bearing test was made on the floor of trench 3. A fourth small trench was made for the purpose of carrying out an impact test at a depth of from 5 to 7.5 cm.

The first trenching pass of the SMSS produced an excavation about 5 to $7.5 \mathrm{~cm}$ deep; the second pass deepened the trench to a depth of 10 to $12.5 \mathrm{~cm}$ (see Figure 25); a third pass produced a trench of from 15 to $17.5 \mathrm{~cm}$ deep. The motion increments produced by a 2-sec retraction command of the SMSS vary with the load acting on the SMSS. When the force reaches a limit determined by temperature and spacecraft voltage, the retraction motor stalls and no retraction is obtained. It was found that the first pass in a trenching operation produced a trench of from 38 to $50 \mathrm{~cm}$ long with about twenty 2-sec retraction commands. Motor stalling was observed in the second (see Figure 20) and third pass in each trench. As many as seventy-five commands were required to complete the third pass through trench 2. This behavior may be explained by the following two statements:

1. When a trenching operation is begun at the surface, the material is free to move sideways out of the way of the advancing scoop. When the trench has been excavated to a depth of several centimeters, the soil scraped from the trench floor accumulates and cannot get out of the way of the advancing, fully packed scoop (Figure 25).

2 . There is a possibility that the lunar material becomes stronger or denser with depth.

Two tests were designed specifically to clarify the second explanation. In the first test, a bearing test was performed on the material at the bottom of trench 3 , at a depth of from 5 to $7.5 \mathrm{~cm}$ below the surface (bearing test 4). In the second test, two open-scoop impact tests were performed on the undisturbed lunar surface adjacent to a trench (impact tests 11 and 12), and an open-scoop impact from the same drop height above the impact surface was made in the bottom of the trench, at a depth of from 5 to $7.5 \mathrm{~cm}$ below the lunar surface (impact test 13).

It is not possible, at this time, to make calculations about the lunar material properties from the trenching operations. Further evaluations of the lunar data must be conducted in combination with SMSS laboratory tests. The explanation for the small motion increments of 
the retraction motor observed under no load must be understood before the retraction forces can be estimated.

Impact. The bearing tests provide information on the static strength properties of the lunar soil. The tests primarily involve the soil's shearing strength, in which density plays a part. Impact tests were conducted to obtain further information on soil density in the absence of the motor current data, which would have enabled the weight of a scoopful of soil to be measured. In such tests, the penetration of the
SMSS into the lunar soil is resisted by both the static strength and the density of the soil. The contribution of the soil's density is greater as the impact velocity increases.

The SMSS is a flexible arm on which vibrations are excited both by the release of the clutch, which initiates an impact test, and by the actual impact. Therefore, a complete analysis of the motion of the SMSS during impact is complicated. At this time, only approximate soil density comparisons can be made between terrestrial laboratory experiments and lunar

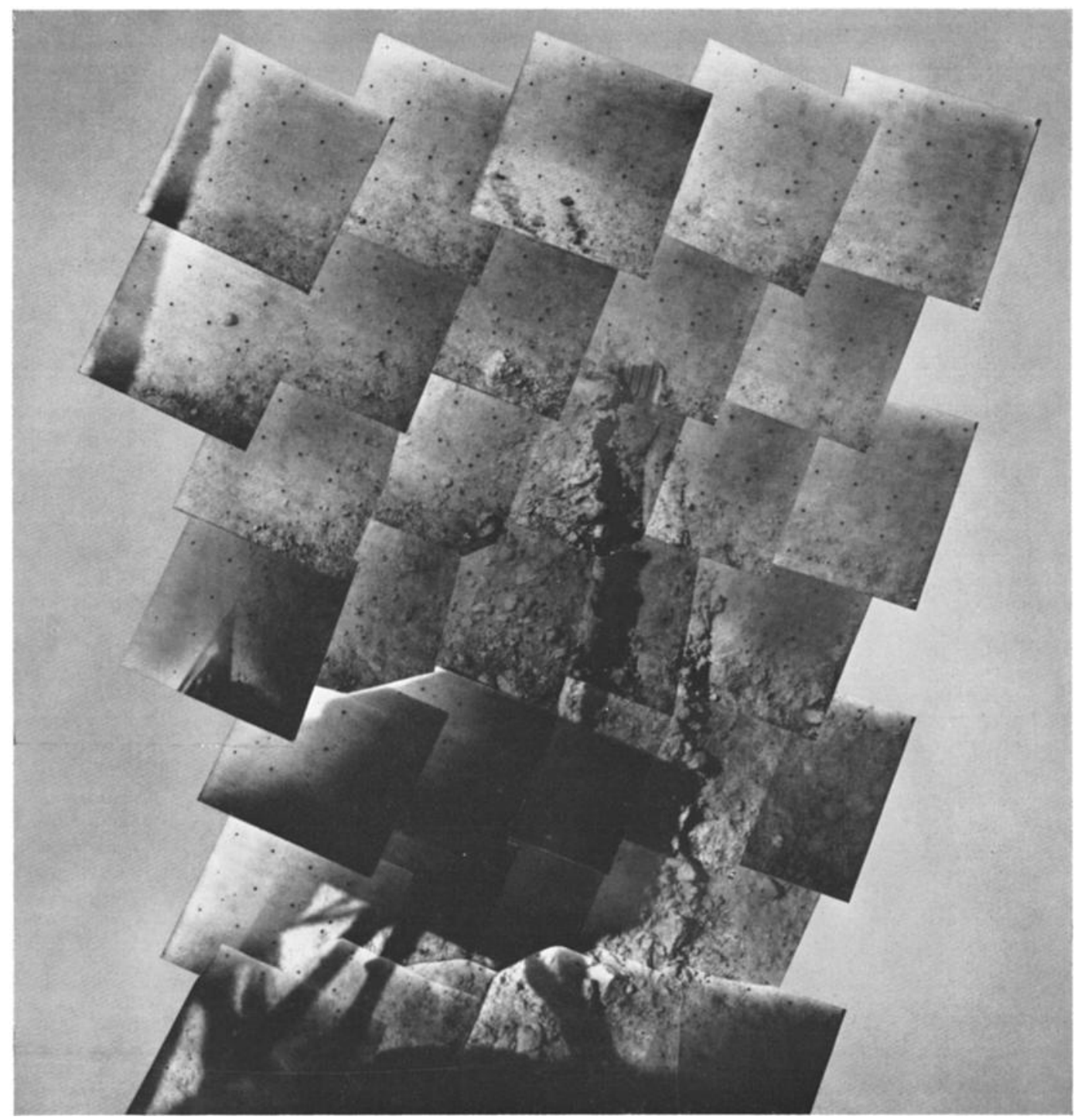

Fig. 22. General area survey of trench 2, improved mosaic. 

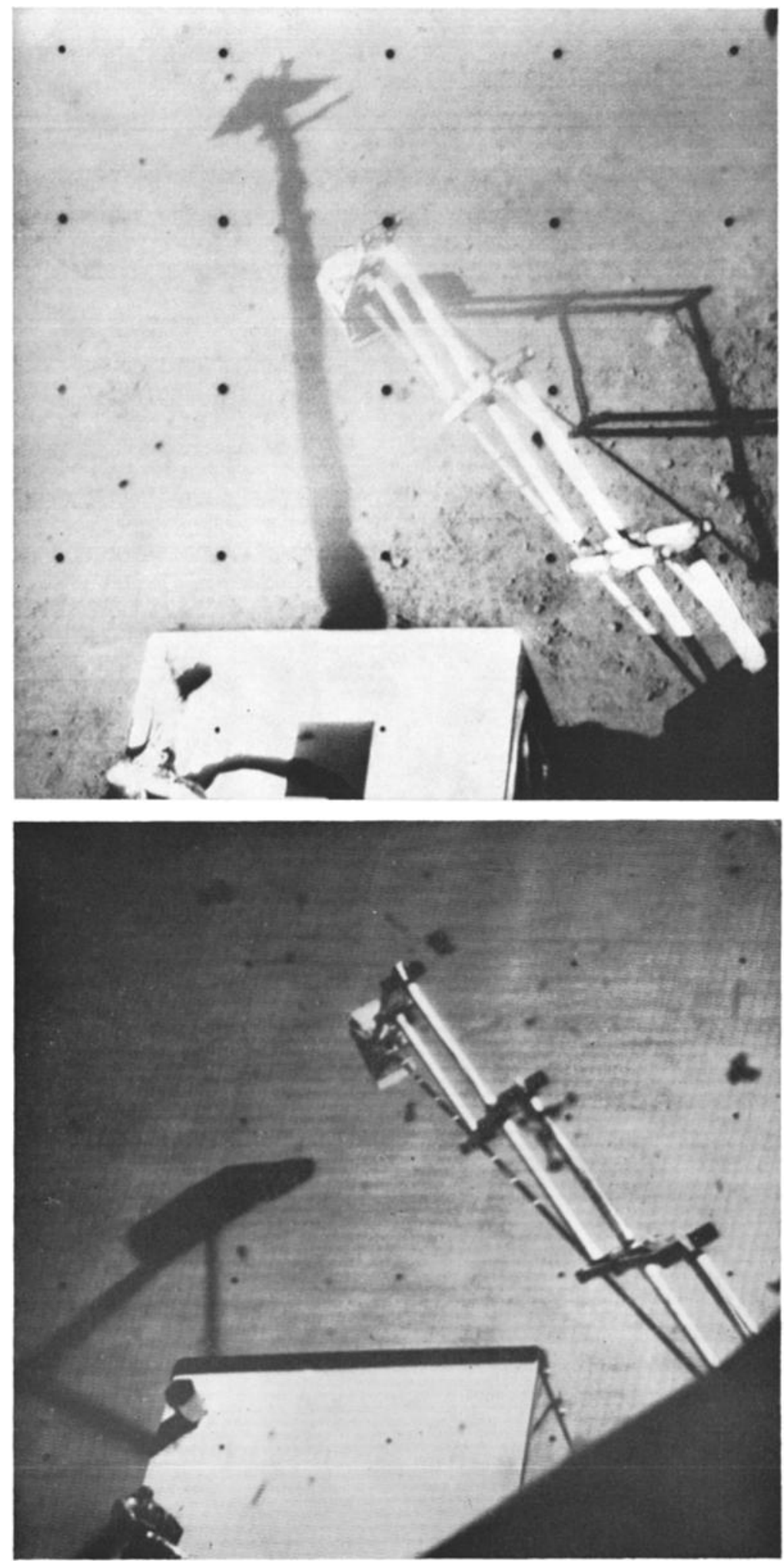

Fig. 23. Example of SETL position (bottom) matching picture from Surveyor (top). Auxiliary battery is at bottom of frame (day $120,15 \mathrm{~h} 30 \mathrm{~m} 32 \mathrm{~s}$ GMT). 
impact tests. On the moon, fourteen impact tests, from a variety of drop heights, were conducted at different locations within the reach of the SMSS on and below the lunar surface. The results of those tests are presented in Table 3 ; their locations are shown in Figure 4 . The drop height given in Table 3 is, at present, approximate. As an example, the result of impact test 3 is shown in Figure 26.

Material handling and dumping. Following a trenching operation, it was frequently found that some of the lunar soil remained stuck to the inside of the SMSS, even when the soil was disturbed considerably. On occasion, this material fell out onto the undisturbed lunar surface, leaving patches or trails of excavated material, as seen in Figure 27.

In the process of excavating the second trench, a lump of lunar material was found below the scoop. The door was closed on the lump to find out if the material was solid or composed of an aggregate of finer particles. Because the scoop door closed with no observable difficulty, it was concluded that the lump was, in fact, an aggregate. As a check, the portion of the lump that was pinched off and enclosed in the scoop was transported to footpad 2 and dumped on the footpad for television observation. The material disaggregated on dumping, as seen in Figures 7 and 8 .

At another location (point $\mathrm{H}$ on Figure 4) an object (about $1 \mathrm{~cm}$ in diameter) with higher albedo than the lunar surface was picked up and transported to footpad 2. While the object was being dumped on the footpad, more soil fell out of the scoop and buried the object. The object was, however, later identified on the footpad. A third object, also of higher albedo and approximately $2.5 \mathrm{~cm}$ in diameter, was located embedded in the lunar soil adjacent to the head of the second trench. It was excavated and picked up in the left side of the scoop, as shown in Figures 11 and 12. In clasping the object, the scoop door exerted a force of about $2.5 \times 10^{\mathrm{a}}$ dynes. The object was restrained by the edge of the scoop, which is $0.1 \mathrm{~cm}$ thick. If it is assumed that the bearing area on the object was $1.2 \mathrm{~cm}$ long and $0.1 \mathrm{~cm}$ wide, the scoop door exerted a

TABLE 3. Summary of SMSS Bearing and Impact Tests

\begin{tabular}{|c|c|c|c|c|}
\hline Test & GMT & $\begin{array}{c}\text { Force, } \\
\text { dynes } \times 10^{5}\end{array}$ & $\begin{array}{c}\text { Penetration, } \\
\text { cm }\end{array}$ & $\begin{array}{c}\text { Drop Height, } \\
\text { cm }\end{array}$ \\
\hline Bearing 1 & Day $112,05 \mathrm{~h} 07 \mathrm{~m} 01 \mathrm{~s}$ & 49 & 2.5 & \\
\hline Bearing 2 & Day $117,08 \mathrm{~h} 45 \mathrm{~m} 20 \mathrm{~s}$ & 27 & 2.5 & \\
\hline Bearing 3 & Day $117,09 \mathrm{~h} 21 \mathrm{~m} 55 \mathrm{~s}$ & 22 & 1.9 & \\
\hline Bearing 4 & Day $118,13 \mathrm{~h} 32 \mathrm{~m} \mathrm{44s}$ & 27 & 0.6 & $\begin{array}{l}\text { (In trench } \\
\text { bottom) }\end{array}$ \\
\hline Bearing 5 & Day $120,15 \mathrm{~h} 35 \mathrm{~m} 31 \mathrm{~s}$ & 27 & 2.2 & \\
\hline Bearing 6 & Day $120,15 \mathrm{~h} 45 \mathrm{~m} 42 \mathrm{~s}$ & $4.5-9$ & $\begin{array}{c}\text { Compressed } \\
\text { clod }\end{array}$ & \\
\hline Bearing 7 & Day $120,15 \mathrm{~h} 48 \mathrm{~m} 50 \mathrm{~s}$ & 27 & 2.9 & \\
\hline Bearing 8 & Day $120,15 \mathrm{~h} 59 \mathrm{~m} 18 \mathrm{~s}$ & 29 & 1.9 & \\
\hline Impact 1 & Day $119,09 \mathrm{~h} 27 \mathrm{~m} \mathrm{02s}$ & & 1.3 & 15 \\
\hline Impact 2 & Day $119,09 \mathrm{~h} 42 \mathrm{~m} 02 \mathrm{~s}$ & & 3.3 & 30 \\
\hline Impact 3 & Day $119,09 \mathrm{~h} 49 \mathrm{~m} 04 \mathrm{~s}$ & & 2.5 & 30 \\
\hline Impact 4 & Day $119,10 \mathrm{~h} 08 \mathrm{~m} 29 \mathrm{~s}$ & & 3.8 & 60 \\
\hline Impact 5 & Day $119,10 \mathrm{~h} 16 \mathrm{~m} 45 \mathrm{~s}$ & & 4.3 & 60 \\
\hline Impact 6 & Day $119,10 \mathrm{~h} 26 \mathrm{~m} 40 \mathrm{~s}$ & & 3.8 & 60 \\
\hline Impact 7 & Day $120,16 \mathrm{~h} 17 \mathrm{~m} 06 \mathrm{~s}$ & & 1.3 & 30 \\
\hline Impact 8 & Day $120,16 \mathrm{~h} 24 \mathrm{~m} 57 \mathrm{~s}$ & & 1.6 & 30 \\
\hline Impact 9 & Day $120,16 \mathrm{~h} 32 \mathrm{~m} 45 \mathrm{~s}$ & & 1.6 & 60 \\
\hline Impact 10 & Day $120,16 \mathrm{~h} 41 \mathrm{~m} 30 \mathrm{~s}$ & & 1.6 & 60 \\
\hline Impact $11^{*}$ & Day $122,12 \mathrm{~h} 38 \mathrm{~m} 33 \mathrm{~s}$ & & 6.3 & 15 \\
\hline Impact $12^{*}$ & Day $122,13 \mathrm{~h} 03 \mathrm{~m} 40 \mathrm{~s}$ & & 6.3 & 15 \\
\hline Impact $13^{*}$ & Day $122,13 \mathrm{~h} 30 \mathrm{~m} 37 \mathrm{~s}$ & & 1.3 & 15 \\
\hline Impact 14 & Day $122,14 \mathrm{~h} 07 \mathrm{~m} 29 \mathrm{~s}$ & & 5.1 & 78 \\
\hline
\end{tabular}

* Scoop open; for all other tests, scoop closed. 

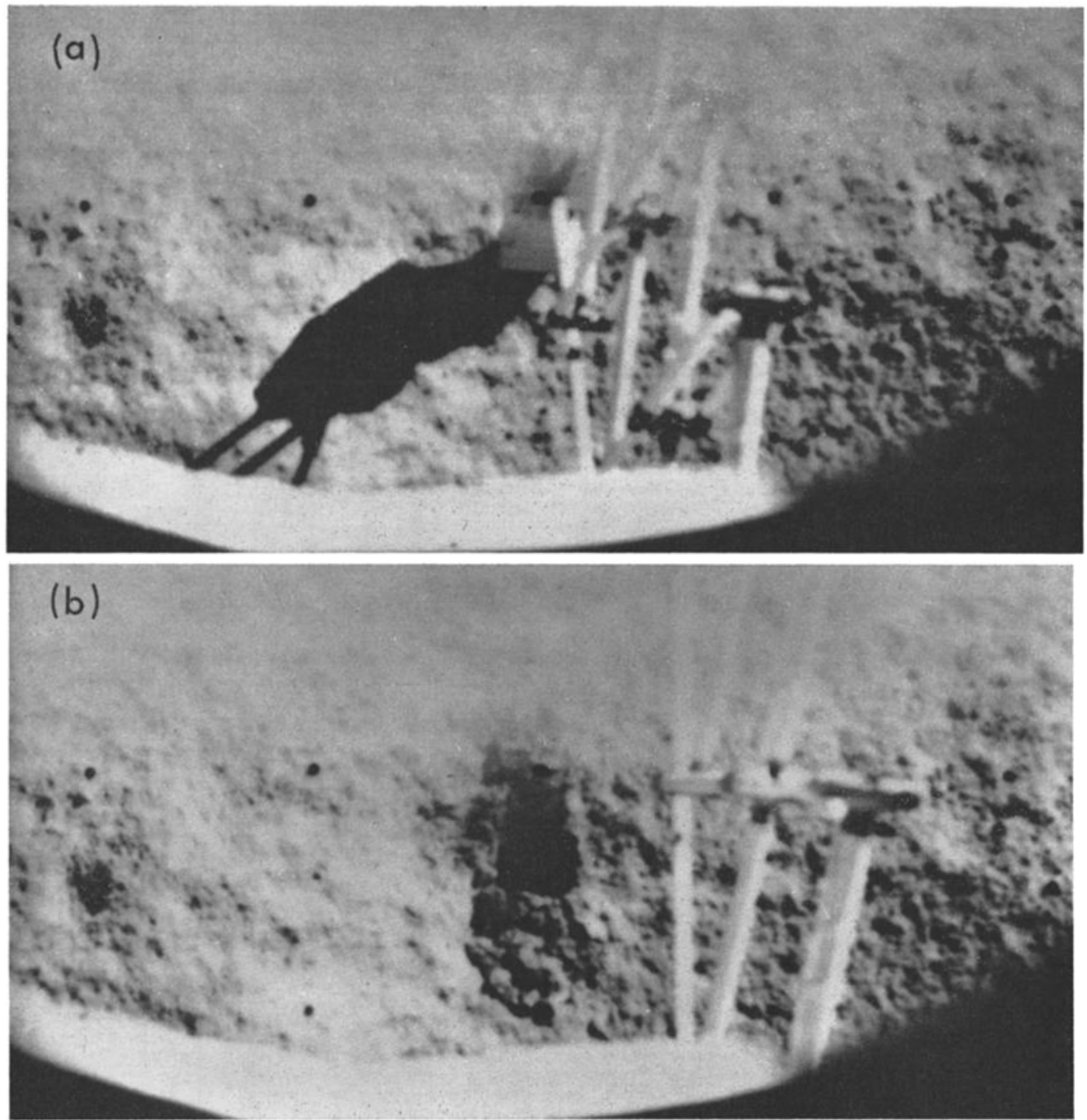

Fig. 24. Picture showing SMSS on April 22, 1967, (a) before (day 112, 05h 07m 01s GMT) and $(b)$ after completion of first lunar surface bearing test (05h $17 \mathrm{~m}$ 27s GMT).

stress of the order of $2 \times 10^{7}$ dynes $/ \mathrm{cm}^{2}$. More of the lighter surface of the object was apparent after it was picked up than when it was embedded. The lower surface, as seen in Figure 12, is darker. The scratch in this lower surface was probably made by the scoop in excavating the object and may indicate that the lower surface is covered with the darker soil.

Homogenity of lunar soil. From the bearing test penetrations, it appears that, considering the probable variation in the force applied to the lunar surface, the lunar material is relatively homogeneous over the test area of $1.9 \mathrm{~m}^{2}$ (see Figure 28).

TABLE 4. Bearing Test Results

\begin{tabular}{lccc}
\hline \multicolumn{1}{c}{ Test } & $\begin{array}{c}\text { Dimension, } \\
\mathrm{cm}\end{array}$ & $\begin{array}{c}\text { Depth of } \\
\text { Penetration, } \\
\mathrm{cm}\end{array}$ & $\begin{array}{c}\text { Pressure, } \\
\text { dynes/cm }\end{array}$ \\
\hline Footpad & 20 & 5 & $4 \times 10^{5}$ \\
SMSS closed & $\mathbf{2 . 5}$ & $\mathbf{2 . 5}$ & $2 \times 10^{5}$ \\
SMSS open & $\mathbf{0 . 3 2}$ & $\mathbf{3 . 8 - 5}$ & $1 \times 10^{6}$ \\
\hline
\end{tabular}


With reference to the impact test area, however, it appears that somewhat less penetration occurred for impact tests 7 through 10 in the vicinity of the auxiliary battery than took place in impact tests 1 through 6 at similar drop heights in the area closer toward footpad 2 (see Figure 29). It should be noted that this variation may be due to changes in the drop heights caused by SMSS elevation motor changes and a result of the spacecraft attitude, rather than to differing lunar surface properties. Also, impact test 4 may have been too close to a previous test. If, however, the differences result from the soil properties, two factors that can effect changes are the strength and the density of the material.

No substantial differences were observed in the resistance of the soil encountered in the different trenching operations.

Depth variation of lunar soil properties. In the bearing tests, the SMSS was lowered by one 2-sec command into the lunar soil. Then, the SMSS was given successive 2-sec commands, which resulted in small additional penetrations. When the movement ceased, the bearing test was terminated. In the absence of motor current measurements, a detailed evaluation of the relation between force and depth is not possible. Characteristically, a penetration of 1.9 to 2.5 $\mathrm{cm}$ was achieved in a bearing test at the lunar surface. However, bearing test 4 , conducted at the bottom of the third trench at a depth of approximately 5 to $7.5 \mathrm{~cm}$ below the lunar surface and probably in disturbed soil, gave a penetration of about $0.6 \mathrm{~cm}$, as shown in Figure 30. This fact, together with the difficulties observed in making the second and third passes through a trench (even considering the effect of trench confinement mentioned), appears to indicate that the lunar soil is firmer or denser below this depth. The comparison of the openscoop impact tests 11 and 12 on the undisturbed

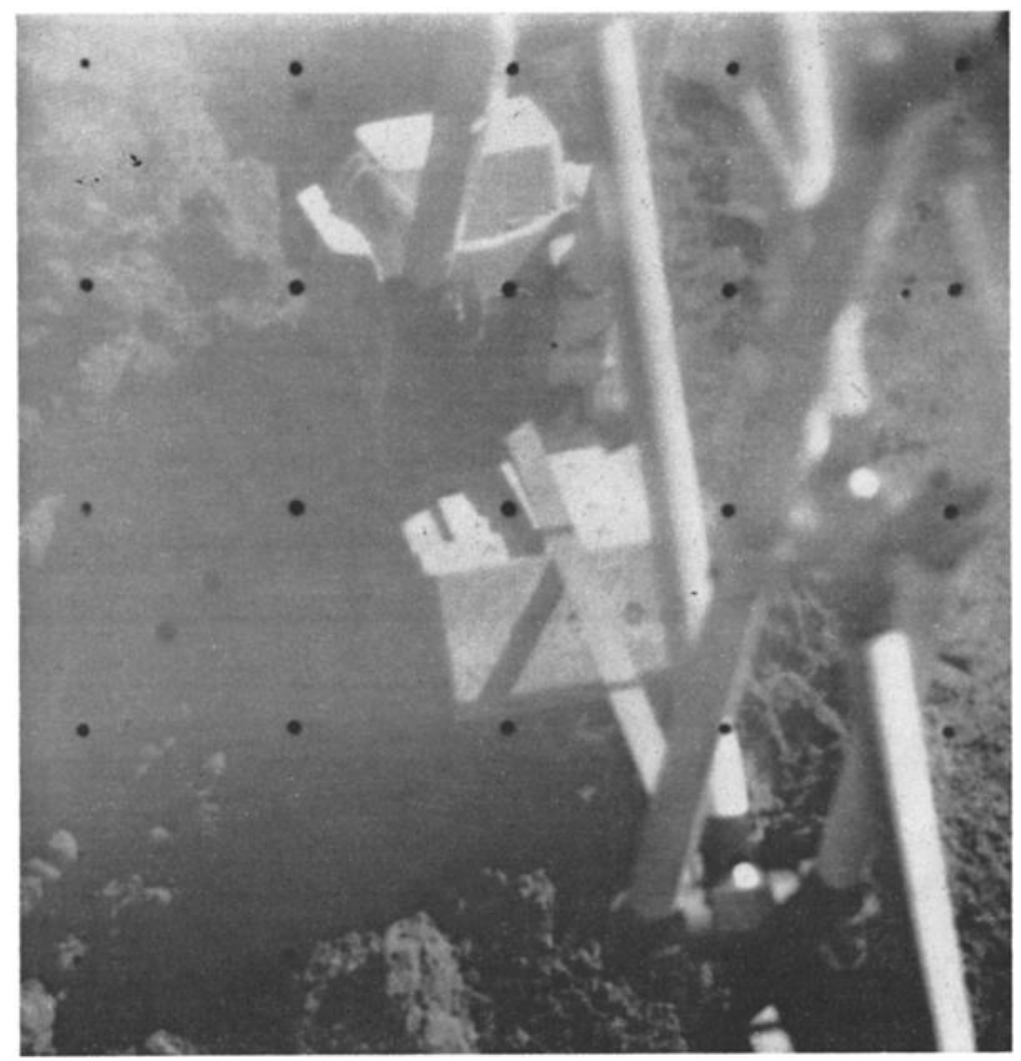

Fig. 25. Second pass of sampler in trench 2 (April 23, 1967). Note material ahead of scoop as it is drawn toward spacecraft (bottom of picture) (day 113, 07h 22m 04s GMT). 


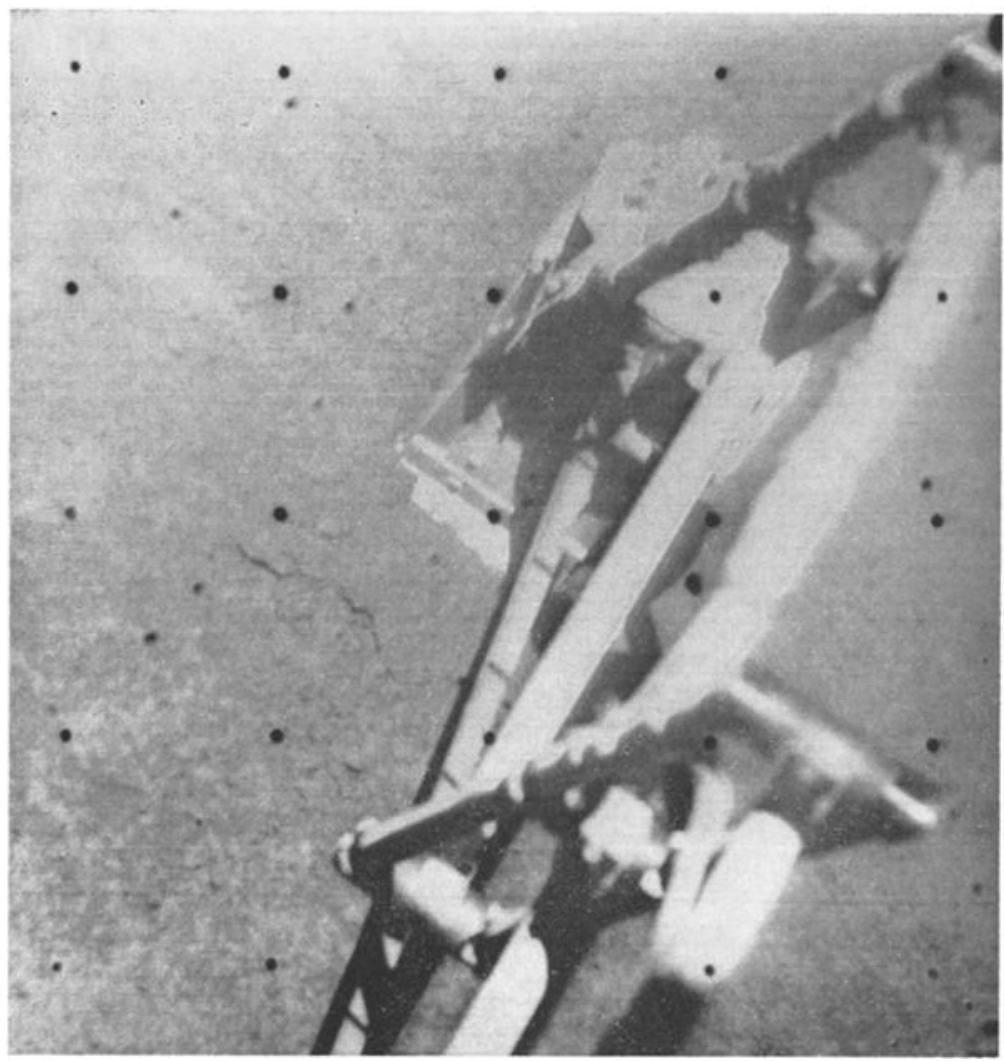

Fig. 26. SMSS scoop is shown embedded in the lunar soil following a drop from a height of about $30.5 \mathrm{~cm}$ in impact test 3 (April 29, 1967). A previous SMSS impact impression is shown in top left corner of picture (day $119,09 \mathrm{~h} 49 \mathrm{~m} 45 \mathrm{~s}$ GMT).

surface with impact test 13 , conducted on the material at a depth of 5 to $7.5 \mathrm{~cm}$ below the surface, confirms that the material is, indeed, stronger or denser below a depth of from 5 to $7.5 \mathrm{~cm}$.

When the scoop was rested on the lunar surface under a vertical force of an estimated $4.5 \times 10^{5}$ to $9 \times 10^{5}$ dynes, little penetration was observed. Therefore, it appears that an extremely soft upper layer does not exist in the immediate vicinity of Surveyor 3. Under the high sun at lunar noon, the detailed texture of the rough surface is no longer visible, and a clear picture of the distance to which the soil is disturbed by a bearing test can be obtained, as seen in Figure 31. The cracks in the ground surface are the surface manifestations of the underground displacement caused by the test. The cracks are not the result of the presence of a surface crust of stronger or more brittle material.
The higher albedo of the undisturbed lunar surface compared with the albedo of the disturbed material in trenches appears to be an extremely shallow effect, as seen in Figures $10 a$ and $10 b$.

As far as can be determined from the SMSS operations, any change in the soil grain size with depth takes place below the resolution of the camera. There is no obvious albedo change with depth once the lighter surface material has been disturbed. The albedo of the smoothed surface caused by bearing test 4 on the undisturbed surface in a trench floor will be studied.

\section{Analysis}

This part of this paper discusses the analyses of the SMSS operations performed to date for the purpose of determining the lunar soil properties. The tests referred to are the bearing tests, because the uncertainty over the retraction motor torque leaves the trenching forces 
still uncertain at this time. Analysis of the impact tests is still incomplete.

Bearing tests. Three bearing tests using different sizes of footing have, in effect, been conducted: the Surveyor footpads with a diameter of 20 to $30 \mathrm{~cm}$, the SMSS with the scoop closed, and the SMSS with the scoop open. The results of these tests are given in Table 4.

It is considered that failure or yielding of the soil by general shear [Scott, 1963] occurred in all these tests. Therefore, the pressure represents the static bearing capacity of the soil at the depth of penetration achieved. The value used for the bearing capacity for the footpad is deduced from the Surveyor 1 landing. It is compatible with the data obtained from the Surveyor 3 landing. The expression for general shear was selected because the soil behavior in a static bearing test appears to be relatively incompressible.

The bearing capacity, $p$, of a footing at a shallow depth, $z$, below the surface of soil is $[$ Scott, 1963] given approximately by the expression

$$
p=G_{c} N_{c} c+G_{\gamma} N_{\gamma} \rho g b+N_{q} \rho g z
$$

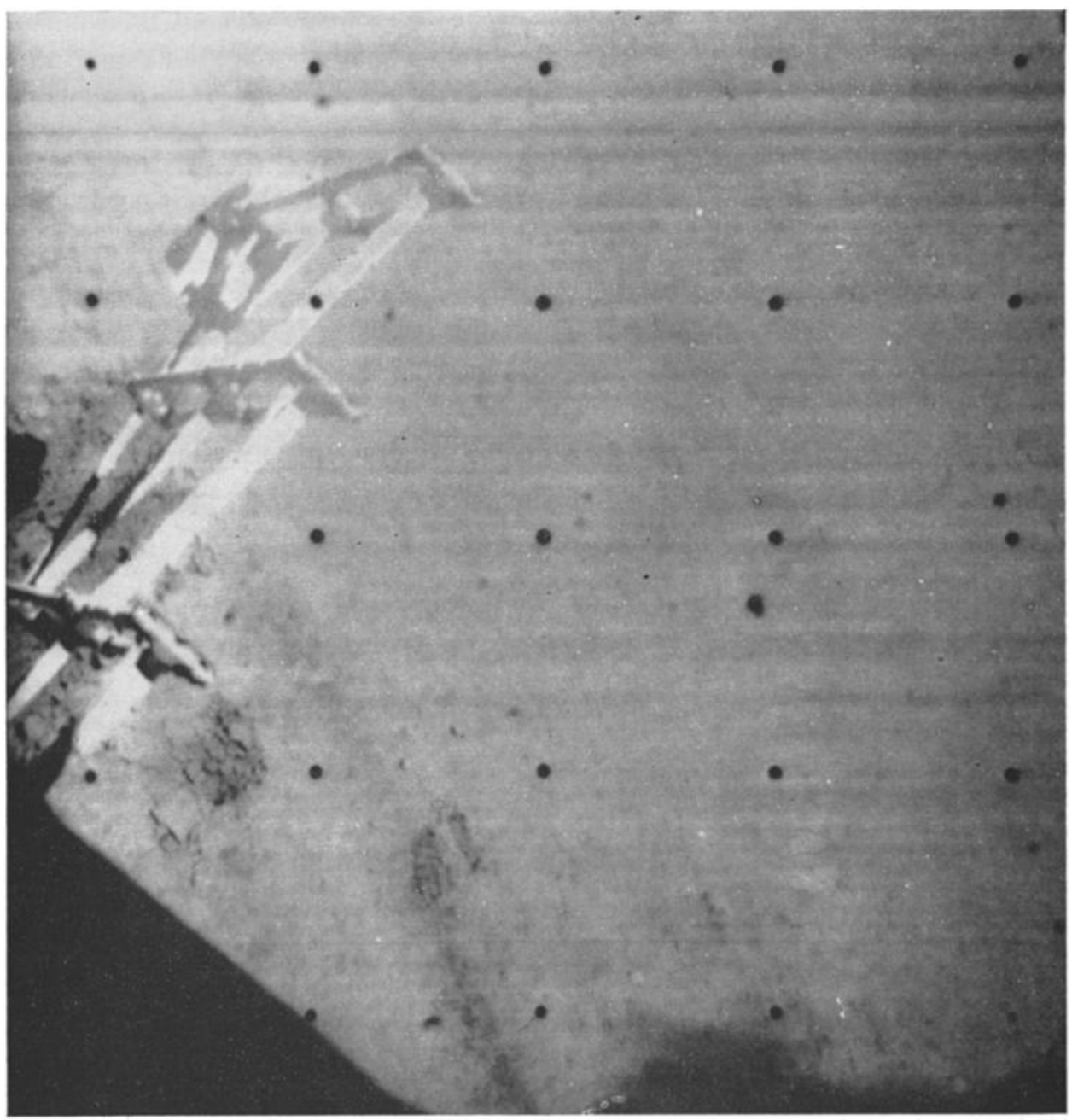

Fig. 27. SMSS in position to begin picking up object. In moving SMSS to this position, material from a trenching operation has fallen from scoop leaving a dark trail across the lunar surface (April 28, 1967). Bearing tests 2 and 3 are seen to the right of the SMSS; trench 3 is obscured by the SMSS (day 118, 09h 48m 08s GMT). 


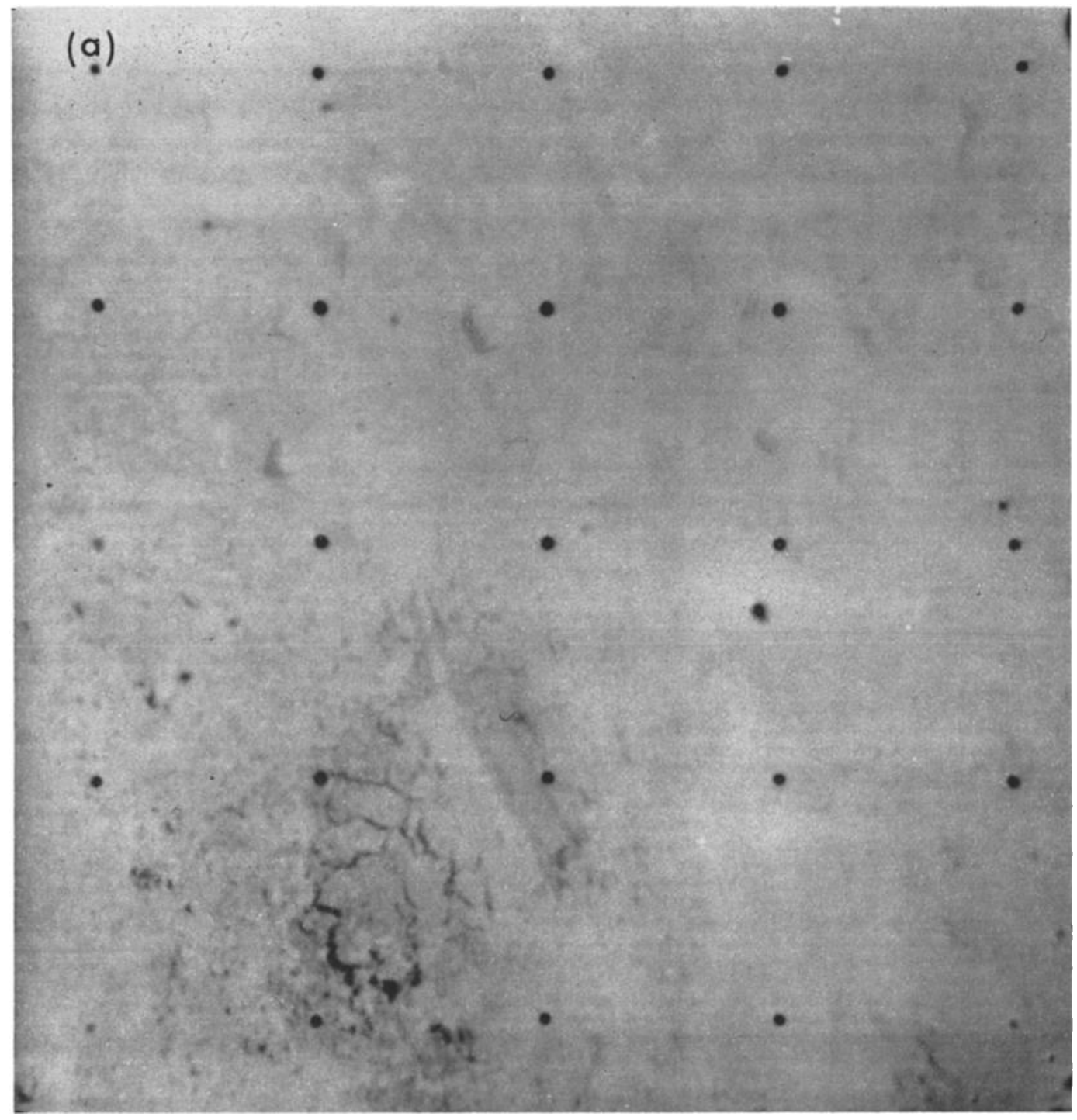

Fig. 28a. Bearing test 3 near footpad, April 27, 1967 (day 117, 09h 30m 12s GMT).

where

$N_{c}, N_{\gamma}$, and $N_{q}$ are dimensionless numbers that depend only on the friction angle $\Phi$ of the soil.

$G_{\circ}$ and $G_{\gamma}$ are dimensionless numbers that depend on the shape of the loaded area. $G_{0}=$ $G_{\gamma}=1$ for a strip footing; $G_{c}=1.3$ for a round footing; $G_{\gamma}=\mathbf{0 . 6}$ for a round footing. $c$ is the cohesion of the soil.

$\rho$ is the density of the soil.

$g$ is the local gravitational acceleration.

$b$ is half the width of the footing.
For the surface sampler base, $G_{c}$ is taken as 1.1 and $G_{\gamma}$ equals 0.9. Equation 1 has been selected, since the lunar soil seems to behave in general shear rather than local shear under a footing. Considering the Surveyor footpad at a $20-\mathrm{cm}$ diameter and the surface sampler with a 2.5-cm width as two bearing tests, two equations can be obtained from equation 1 . For the present (ignoring the open-scoop test), there are three unknowns, $\rho, c$, and $\Phi$ (because $N_{e}, N_{\gamma}$, and $N_{q}$ are functions of $\Phi$ only), to be determined from the two equations, if it is assumed 
for the present that the lunar soil is homogeneous to a depth of several centimeters.

There are many ways of determining the soil parameters. The method selected here is to choose values of $\rho$ compatible with the observation that the material is granular, is relatively incompressible, and has a deformational behavior qualitatively similar to that of terrestrial soils. For each density, values of cohesion $c$ and internal friction $\Phi$ of the lunar soil may be calculated. The values obtained are discussed in terms of the observed behavior.
For the calculations, densities of $1.0,1.5$, and $2.0 \mathrm{~g} / \mathrm{cm}^{2}$ have been selected. For a solid mineral component density of $3 \mathrm{~g} / \mathrm{cm}^{3}$, the porosities shown have been calculated. The results are given in Table 5. To show the variation that can be expected in the results, the values of cohesion and friction angle (values in parentheses) were calculated for a Surveyor footpad-bearing capacity of $2.8 \times 10^{5} \mathrm{dynes} / \mathrm{cm}^{3}$. This value may represent a lower limit of the bearing capacity at the footpad scale.

For a soil composed of solid mineral particles

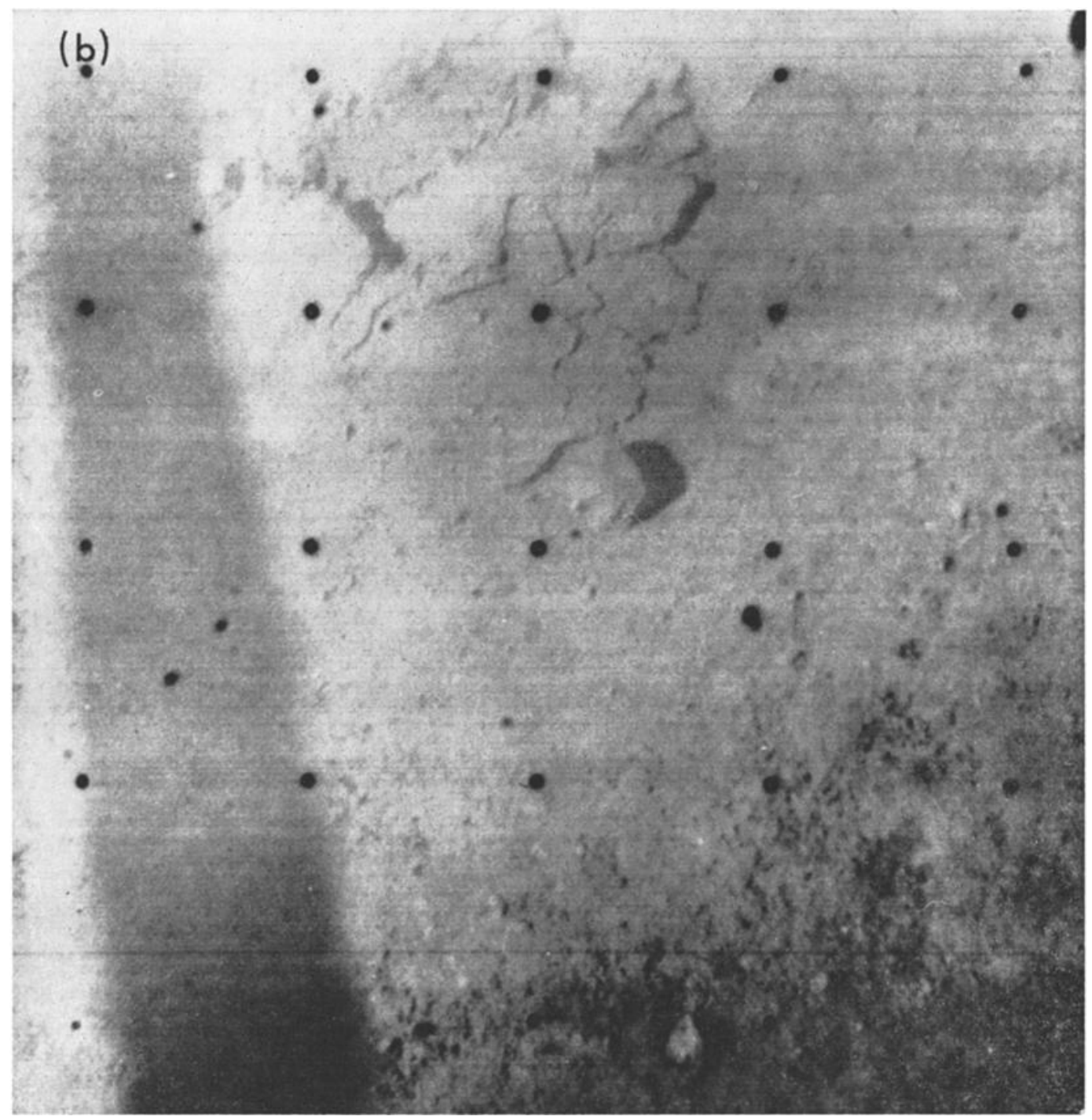

Fig. 28b. Bearing test 5 near auxiliary battery, April 30, 1967 (day 120, 15h $40 \mathrm{~m} \mathrm{08s} \mathrm{GMT).}$ There is an obvious similarity in the imprints of these two tests, which are separated by a distance of several meters. Note small object below imprint in picture. 


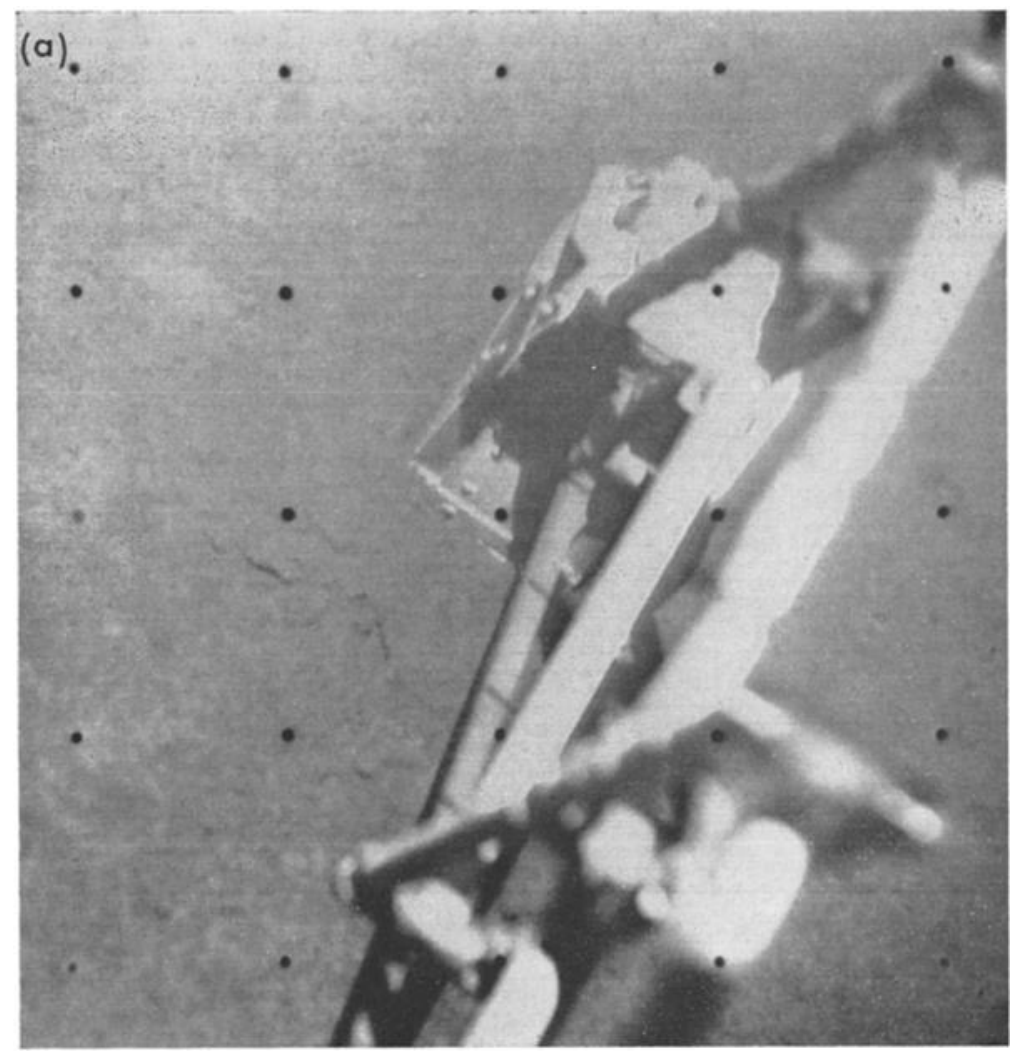

Fig. 29a. Impact 4 from a height of about $60.9 \mathrm{~cm}$ near footpad 2, April 29, 1967 (day 119, $10 \mathrm{~h} 08 \mathrm{~m} \mathrm{29s}$ GMT).

of ordinary terrestrial density (about $3 \mathrm{~g} / \mathrm{cm}^{3}$ ), a density of $1.0 \mathrm{~g} / \mathrm{cm}^{3}$ represents a material with a large proportion of void spaces, or high porosity. Such a soil does not exhibit the generally incompressible behavior shown by the lunar soil in the bearing tests. In addition, the friction angle of a particular soil increases as the density increases and is in the range of $25^{\circ}$ to $45^{\circ}$ for soils with low to high densities. It is seen from Table 5 that the lower the density of the material is assumed to be, the higher must be the friction angle in order to explain the observations.

If the lunar soil were composed of porous mineral particles that did not break up during the bearing tests, the incompressible behavior could occur and the material could have a friction angle of $40^{\circ}$ and at the same time possess a low density. A large proportion of the lunar surface material is, however, apparently composed of particles smaller than from $\mathbf{4 0}$ to $\mathbf{5 0}$ $\mu \mathrm{m}$ in diameter. These small particles would have to be porous for a lunar soil of low density to exhibit the observed mechanical behavior. Although this possibility is not excluded, it seems more reasonable to conclude from the calculations (see the tabulation) that the lunar surface material has a density in the range of $1.5 \mathrm{~g} / \mathrm{cm}^{3}$ with an accompanying cohesion of about $1.4 \times 10^{3}$ dynes $/ \mathrm{cm}^{2}$ and a friction angle of about $39^{\circ}$.

In bearing tests of this type, the soil is typically uplifted and disturbed on the surface to a distance that depends on the angle of internal friction of the material. For the $2.5-\mathrm{cm}$ width of the SMSS base, a material with an angle of friction of $30^{\circ}$ would be disturbed to a distance of about $7.5 \mathrm{~cm}$ from the edge of the base, and a material with an angle of friction of $40^{\circ}$, to a distance of about $17.5 \mathrm{~cm}$. It is observed in the SMSS bearing tests under a high sun angle (Figure 31) that soil disturbance takes place to a distance of at least 10 to $12.5 \mathrm{~cm}$, indicating an angle of internal friction of at least $35^{\circ}$. The 
nature of the displacement phenomenon observed in the bearing tests indicates that the soil density does not change appreciably during the test.

For any of the discussed soils, a calculation using equation 1 applied to the open-scoop SMSS bearing test indicates that a much greater depth of penetration should have been obtained under the vertical force employed. The indication is, therefore, that below a depth of about 5 $\mathrm{cm}$ the lunar soil is substantially firmer or denser, which confirms the soil behavior observed in the trenching tests.

This increase in strength affects the calculations of the soil properties based on the bearing tests, because the size and depth of penetration of the spacecraft footpads are such that the assumption of vertical homogeneity cannot be made. In this case, equation 1 cannot be used and the relative values in the tabulation are not correct, because the firmer soil (assuming it existed also at the Surveyor 1 site) would affect the penetration of the spacecraft footpad. In a homogeneous material of the same average characteristics as the top $5 \mathrm{~cm}$ of the lunar soil, the spacecraft footpad would have penetrated deeper at the same applied pressure. If this consideration is used to reevaluate the data, it appears that (for all the assumed densities) friction angles would be from $2^{\circ}$ to $3^{\circ}$ lower and the cohesion would be perhaps $7 \times 10^{2}$ dynes $/ \mathrm{cm}^{2}$ higher. The small amount of cohesion apparently present in the lunar soil leads to the tentative conclusion that Van der Waals forces, rather than primary bonding forces, are causing the cohesion.

It is possible that the increase of strength with depth is a phenomenon associated with the Surveyor 3 landing position, because legs 2 and 3 of the spacecraft apparently rest on or near

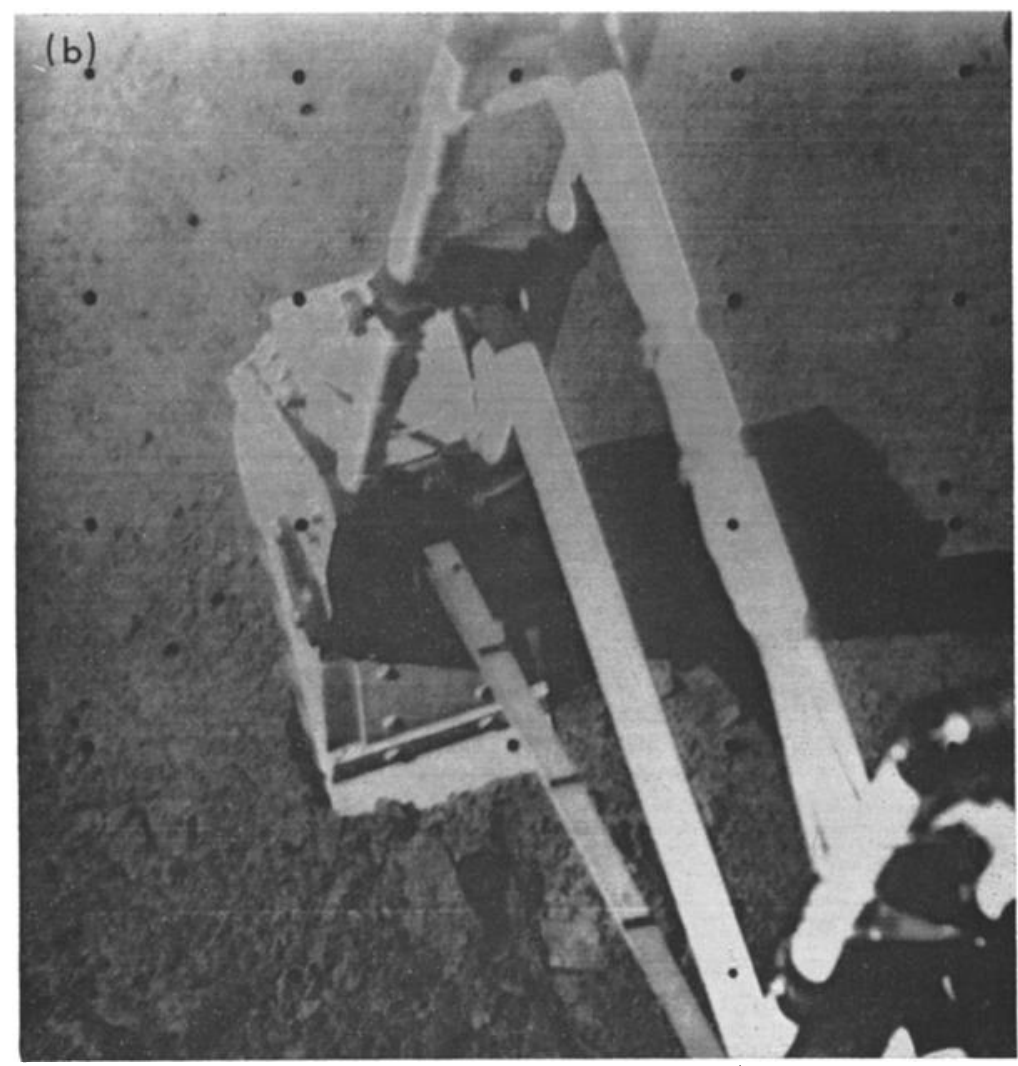

Fig. 29b. Impact 10 from a height of about $60.9 \mathrm{~cm}$ near auxiliary battery, April 30 , 1967 (day $120,16 \mathrm{~h} 41 \mathrm{~m} \mathrm{30s}$ GMT). There is a difference in the depths of penetration in these two tests. 


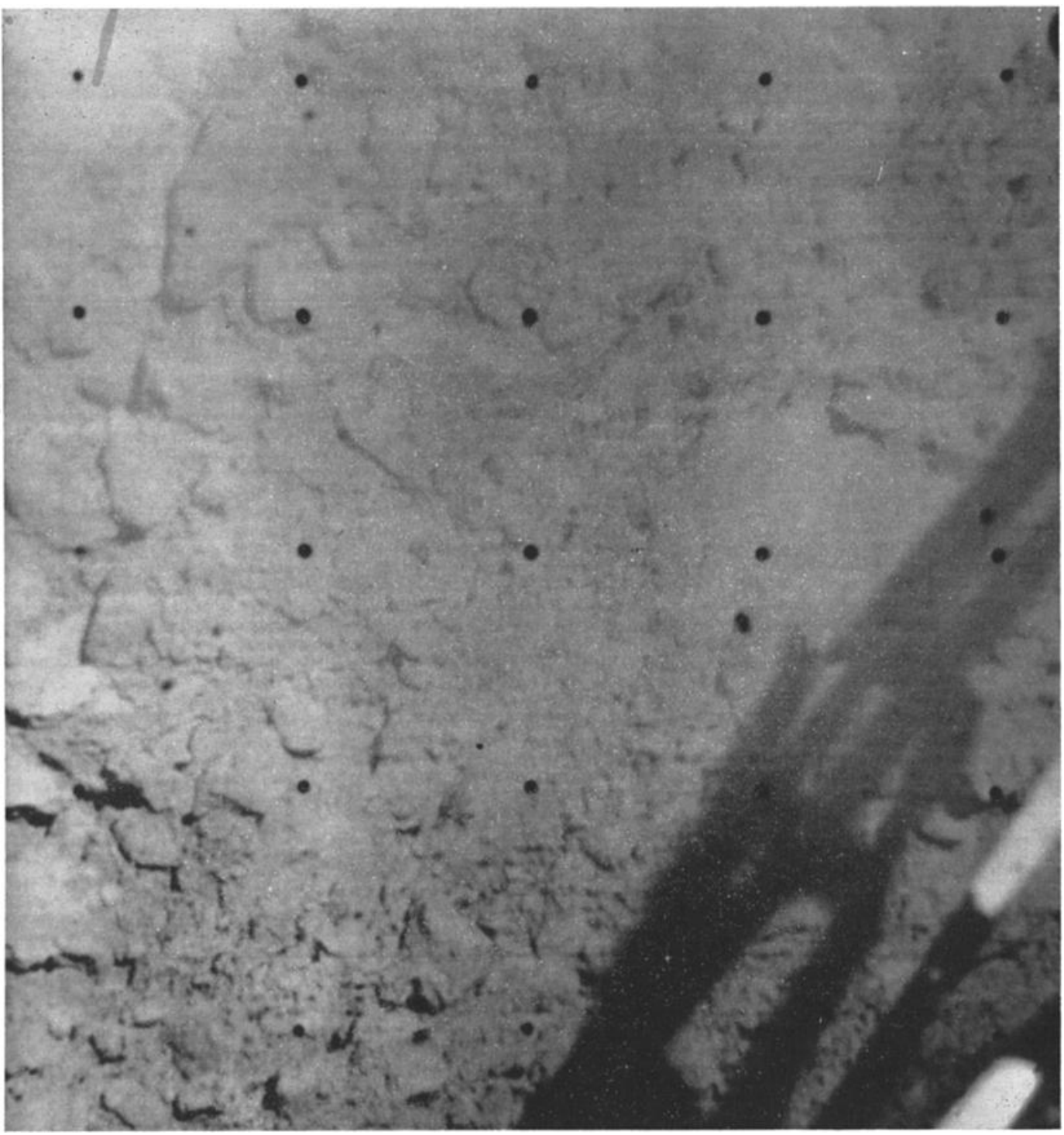

Fig. 30. Bearing test 4 impression in bottom of trench 3 at a depth of 5.1 to $7.6 \mathrm{~cm}$ below lunar surface (April 28, 1967). Depth of impression estimated from shadow. Soil broken up by trenching operation is visible (day 118, $13 \mathrm{~h} 35 \mathrm{~m} 22 \mathrm{~s}$ GMT).

the rim of a small shallow crater and the SMSS tests were performed on the rim material. If this is not the case and if the increase in strength with depth is a general lunar feature, there is no obvious reason why there should be a sudden increase at the 5-cm depth. It is possible, therefore, that there is a gradual increase with depth. The lack of SMSS motor current data precludes any confirmation of this property assumption.
Because trenching was performed to depths greater than $5 \mathrm{~cm}$, further analysis of the trenching information may yield quantitative results on the soil profile below that depth.

Trenching. The reactions of the retraction motor are still being analyzed to determine the reasons for the anomalous behavior. The forces applied by the SMSS to the lunar soil during trenching operations remain unknown.

In an attempt to measure these forces, trench 
4 was dug on day 122 , after turning on the strain gages on Surveyors' shock absorbers. A preliminary analysis of the static strain gage readings immediately following the landing indicates that a change in the force in a shock absorber of amount greater than $4.5 \times 10^{\mathrm{a}}$ dynes could be discriminated in the strain gage record. The strain gage traces obtained during the trenching test show no indication of any load level change. It is, therefore, tentatively concluded from further analysis that the SMSS was exerting a retraction force of less than $4.5 \times 10^{8}$ dynes on the lunar surface during the formation of trench 4 . Still further reduction of the strain gage records is planned.

Impact tests. A complete analysis of the impact tests cannot be given at this time. However, the velocity of the surface sampler at contact with the lunar surface from a drop height of $60 \mathrm{~cm}$ (corresponding approximately to four 2 -sec elevation steps) can be estimated to be about 2.1 to $2.5 \mathrm{~m} / \mathrm{sec}$. Laboratory tests have

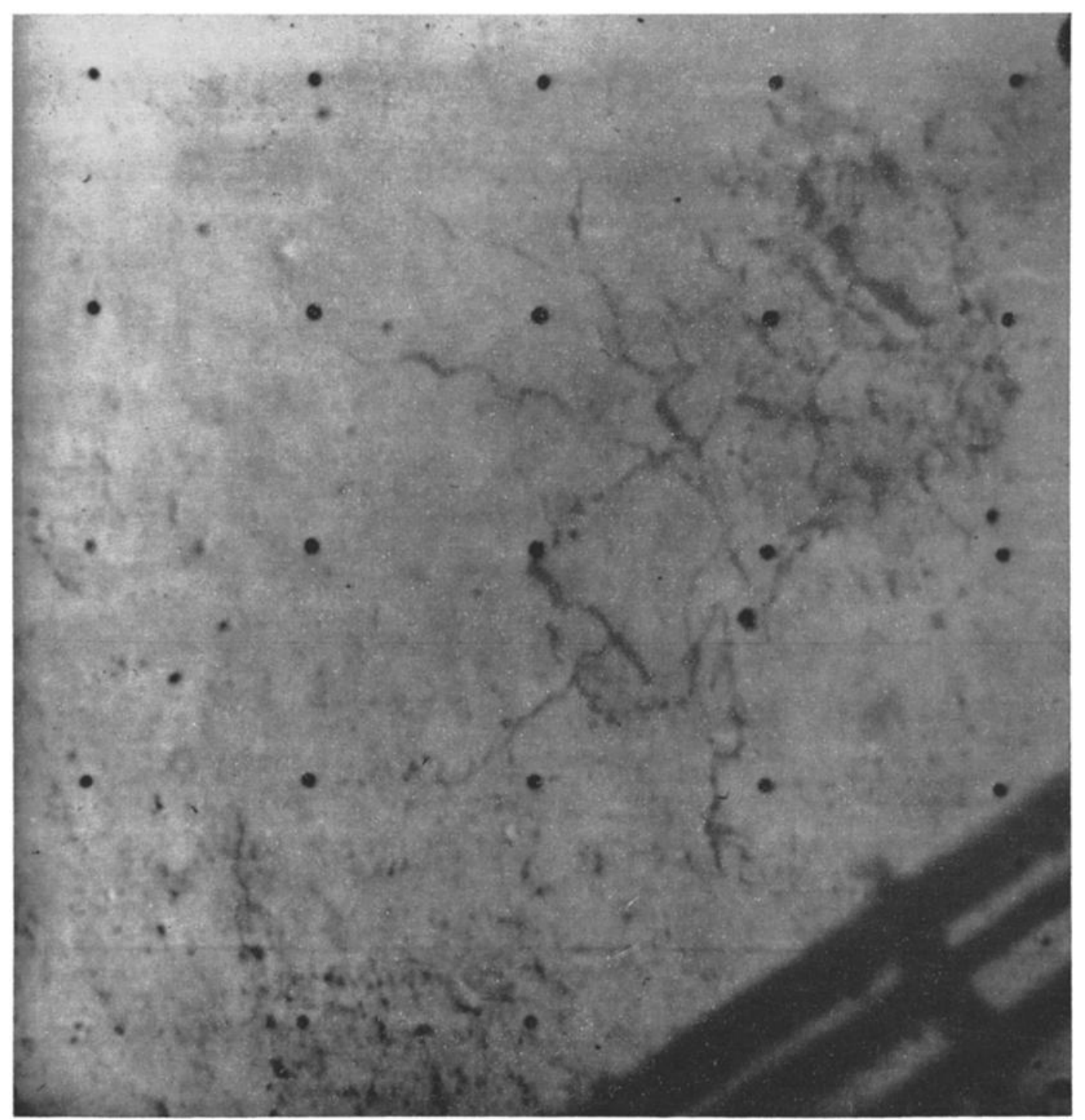

Fig. 31. Imprint of bearing test 2 observed at high sun (April 27, 1967). The cracks caused by the test and extending to the surface of the soil are clearly seen (day 117, 08h $56 \mathrm{~m}$ 45s GMT). 
TABLE 6. Soil Property Calculations

\begin{tabular}{cccc}
\hline $\begin{array}{c}\text { Density, } \\
\text { g/cm" }\end{array}$ & Porosity & $\begin{array}{c}\text { Cohesion, } \\
\text { dynes/cm, }\end{array}$ & $\begin{array}{c}\text { Angle of } \\
\text { Friction, } \\
\text { deg }\end{array}$ \\
\hline 1.0 & 0.67 & $9 \times 10^{2}\left(5.5 \times 10^{9}\right)$ & $42(33)$ \\
1.5 & 0.50 & $1.4 \times 10^{8}\left(8 \times 10^{9}\right)$ & $39(30)$ \\
2.0 & 0.33 & $17 \times 10^{2}\left(1 \times 10^{4}\right)$ & $37(27)$ \\
\hline
\end{tabular}

been performed on earth with a prototype SMSS striking various soils at a range of velocities. For a slightly higher impact velocity than the value given for the SMSS moon impacts, laboratory tests on densely packed dry sand (density about 1.7 to $1.8 \mathrm{~g} / \mathrm{cm}^{3}$ ), with the scoop closed, have given penetration depths of 1.6 to $1.9 \mathrm{~cm}$. Such a soil has a friction angle of about $40^{\circ}$ and is essentially cohesionless. Comparison of the SMSS lunar impact tests with the terrestrial tests indicates that the material densities are comparable, although preliminary analyses indicate that penetration depths at these impact velocities are not very sensitive to density. The density of the terrestrial tests (about $1.5 \mathrm{~g} / \mathrm{cm}^{3}$ ) would be compatible with the value in the analysis of the static lunar results. The effect of the stronger or denser lunar soil layer below a depth of from 5 to $7.5 \mathrm{~cm}$ on the impact test results remains to be investigated. It would tend to lessen the penetrations.

Material handling. Because the disturbed lunar soil remains in the open SMSS scoop above the lunar surface, it can be calculated that it possesses a cohesion greater than about $3 \times 10^{2}$ dynes $/ \mathrm{cm}^{2}$ for an assumed density of about $1.5 \mathrm{~g} / \mathrm{cm}^{3}$. Since the walls of the trenches have not collapsed at a depth of 15 to $17.5 \mathrm{~cm}$, it appears that the cohesion may be at least $10^{3}$ dynes $/ \mathrm{cm}^{2}$. In one impact test conducted with the scoop open, a quantity of soil was dumped on the lunar surface almost equal in volume to the capacity of the scoop, as near as can be estimated. In such an impact test, the maximum deceleration is in the range of from 5 to 10 earth $g$. Therefore, the upper limit of the cohesion of the disturbed soil to the scoop can be estimated as being about $10^{4}$ dynes $/ \mathrm{cm}^{2}$.

In one bearing test, an object (see Figure $28 b$ ) resting on the lunar surface was depressed and found to crumble under a relatively gentle pressure (contact 3, item $\mathrm{T}$ in Figure 4). It is concluded that this object was an aggregate of smaller particles, as was the clod of material broken by the scoop door at the foot of trench 2. One of the objects of higher albedo that was picked up seemed to have a substantially greater strength than these clods, and it may be termed a rock.

Acknowledgments. We express special appreciation to M. C. Clary of JPL for his analysis of the performance of the mechanism and auxiliary during the mission.

The work described herein is performed by the senior author under contract JPL-CIT 69811 with the Jet Propulsion Laboratory. The surface sampler was designed and constructed by Hughes Aircraft Company, El Segundo, California.

\section{REFERENCES}

Scott, R. F., Principles of Soil Mechanics, Addison Wesley, Reading, Mass., 1963.

Scott, R. F., Soil mechanics surface sampler experiment for Surveyor, J. Geophys. Res., 7Q(2), 827, 1967.

(Received January. 23, 1968.) 